\title{
ثورة البيانات
}

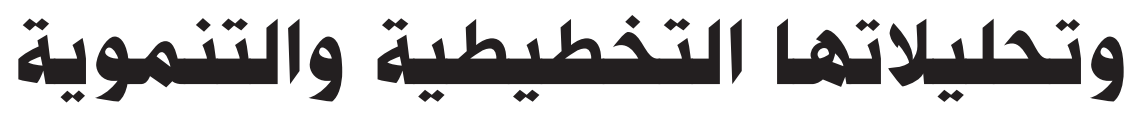

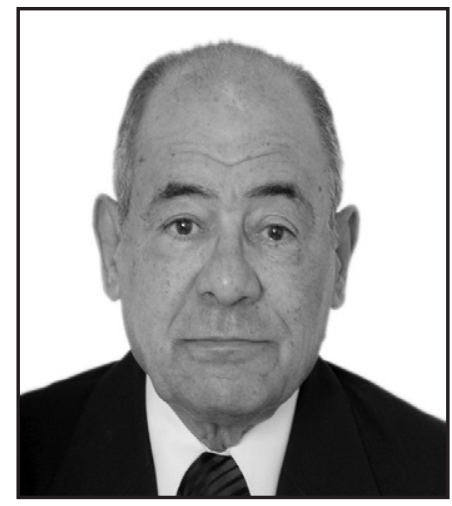

أ.د. محمد محمد الهادي

أستاذ الحاسب الآلي ونظم المعلومات

بأكاديمية السادات للعلوم الإدارية

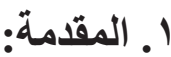

الآداب المنشورة والمتاحة حاليا مكتظة بالتقارير حول

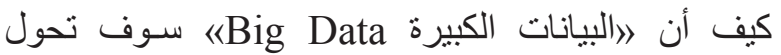
مجالات اعمال الثركات والمات المصلح الحكومية وأوجه التنمية

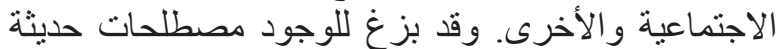

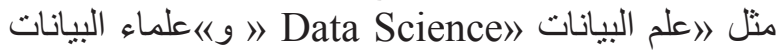
كان من الصعب السماع عنهما في السنو ات التئل القليلة الماضية.

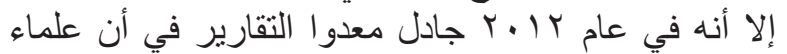

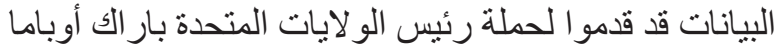
الحد التنافسي للانتخابات الرئيسية. (Google Search for

("Obama campaign" AND data mining كما أن الخبراء والمتخصصين الذين بعملون في وادي السيليكون Silicon valley بولاية كاليفورنيا في في الائي

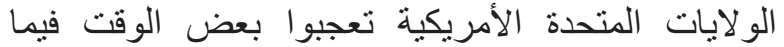
يتصل بالتطورات الحادثة المرتبطة بثورة البيانات البات من فئن خلال ظهور ظاهرة البيانات الكبيرة ومدي ثنأثير ها على بلى

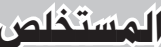

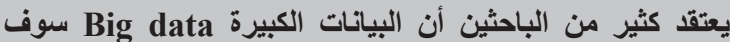

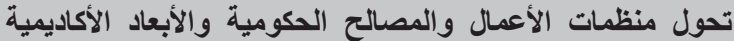

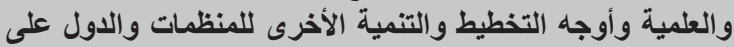

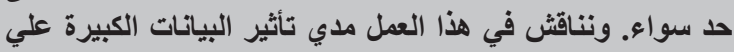

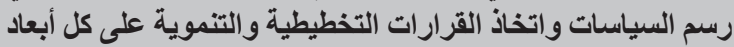

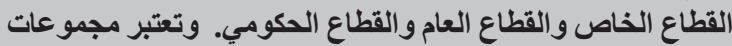

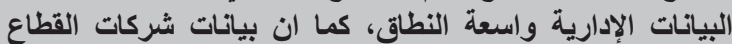

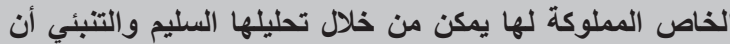

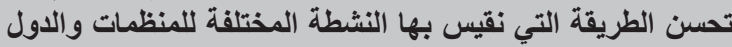
على حذ سواء وتتبع ذلتك وتضييقه بطريقة كبيرة. كما أن ظاهرة

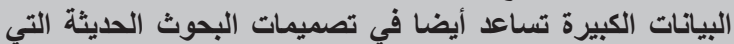

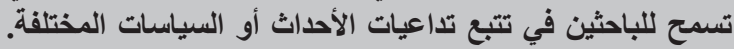

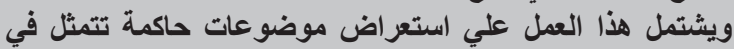

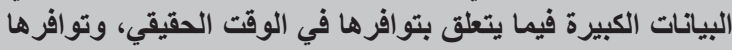

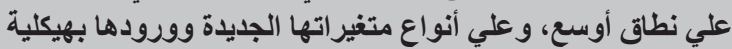

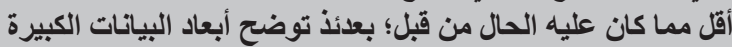

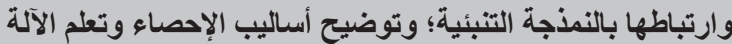

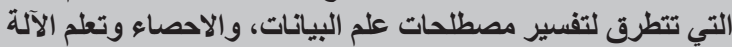

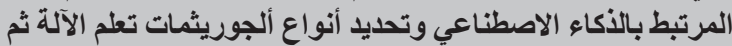

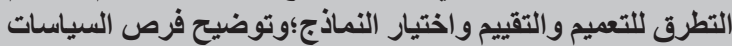

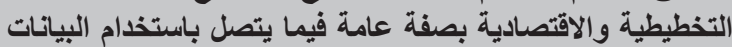

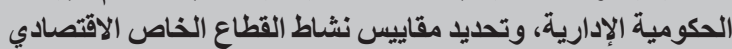

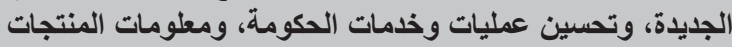

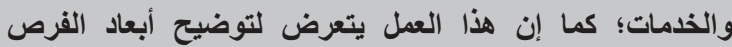

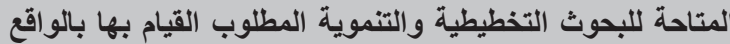

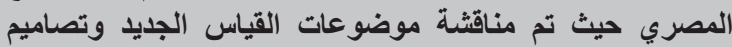

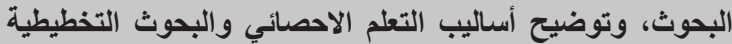

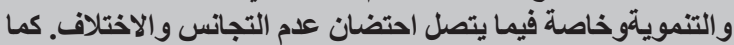

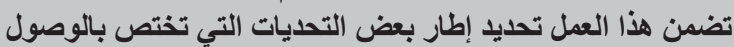

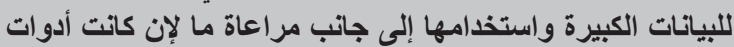

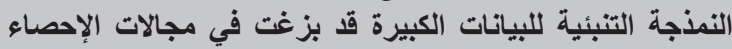

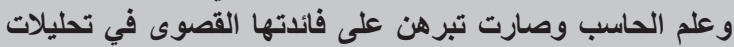
لتخطيط والتنمية الاقتصادية المنشودة للوطن.

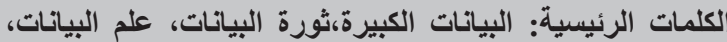

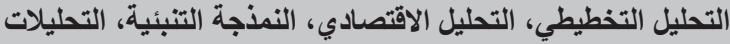
التبنئية، البيانات الإدارية، الإحصاء، تعلم الآلّة. 
للحصول على البيانات الحكومية في القطاع الخاص،

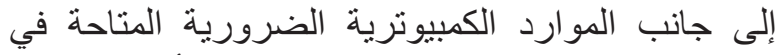

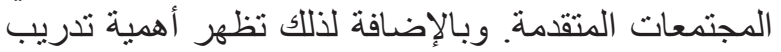

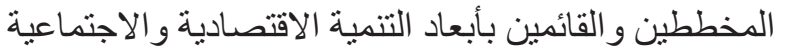

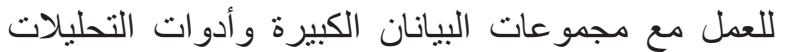
التنبئية المتطلبة في ذلك.

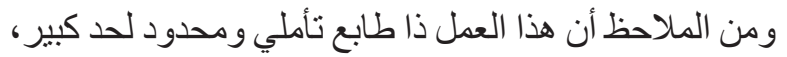

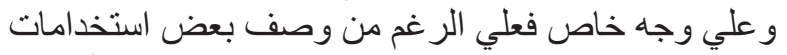

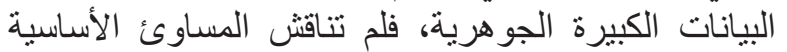

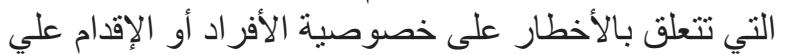

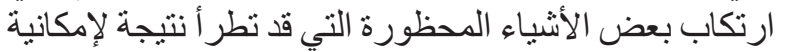

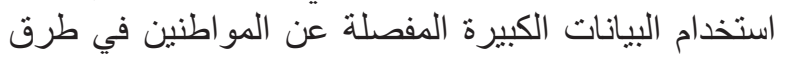

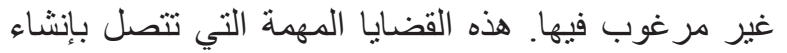

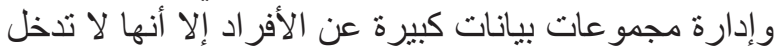
في نطاق هذا العمل.

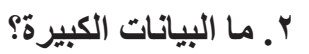
من عشرين أو ثلاثثين عاما مضت، كاتهات الات البيانات عن الأنشطة الاجتماعية والاقتصادية نـادرة نسبيا. وقد تغير

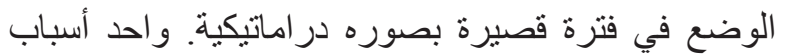

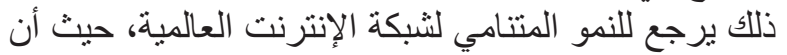

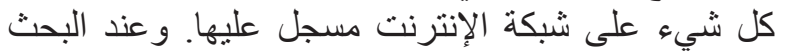

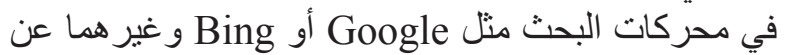

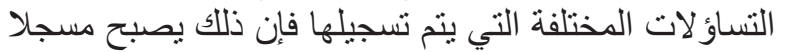

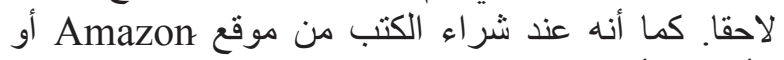

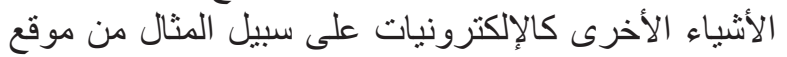
eBay

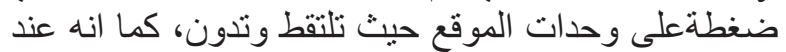

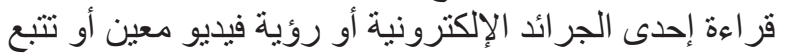

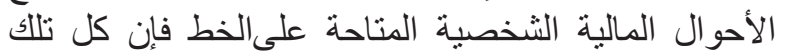

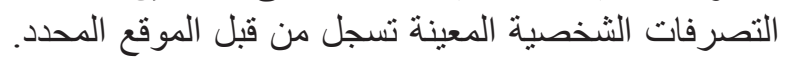

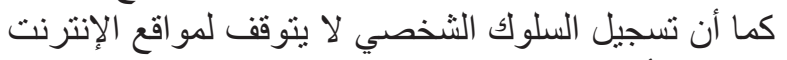

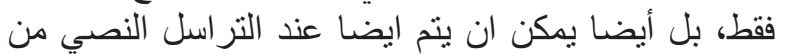

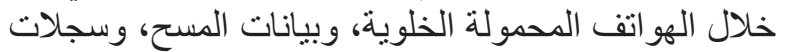

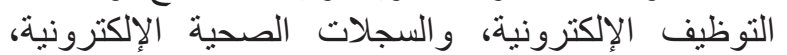

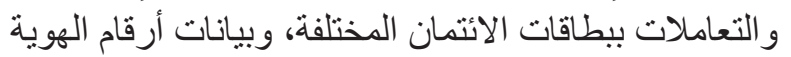

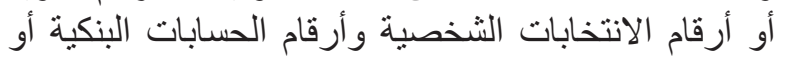

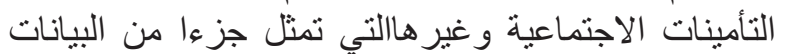
التي نتركها خلفنا حاليا.

وفي هذا الإطـار يمكن اعتبار مثنال معين يوضح هذا هذا

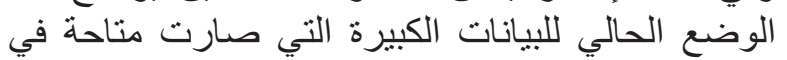

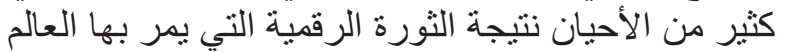
الحديث كالبيانات المجمعة من محلات تنجة لتهارة التجزئة
مخرجاتهم التكنولوجية التي سوف يكون لها مردود إيجابي على التخطيط و التتمية بأبعادها الاجتماعية والاقتية لتصادية

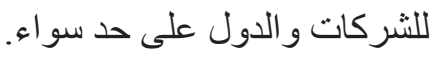

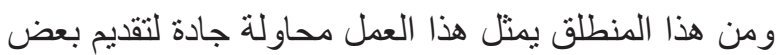

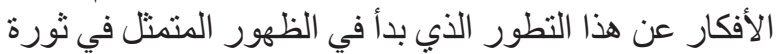

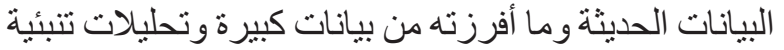

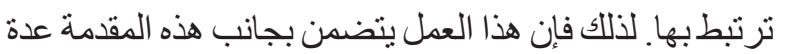

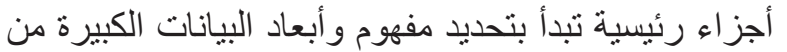

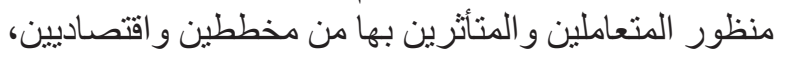

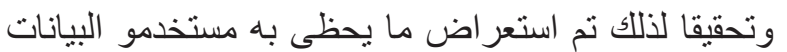

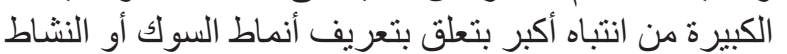

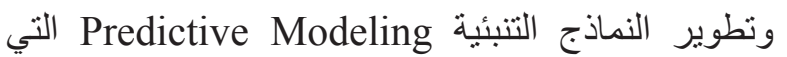

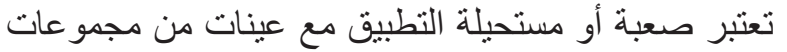

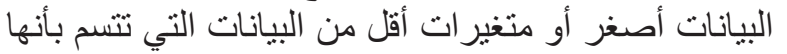

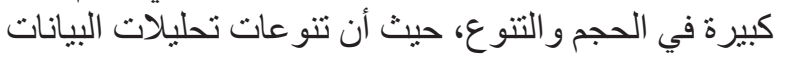

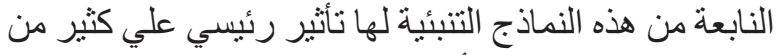

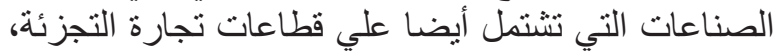

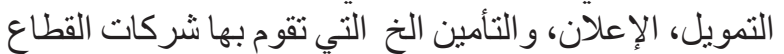

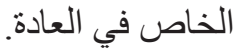
كما يناقش هذا العمل كيف أن البيانات الكبيرة الجديدة قد تؤثر

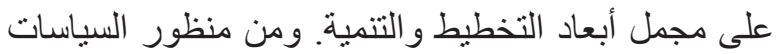

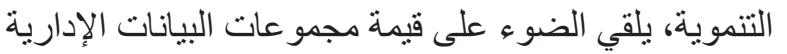
الكبيرة، و على القدرة في استيعاب و التقاط بيانات التبات العمليات الإنات

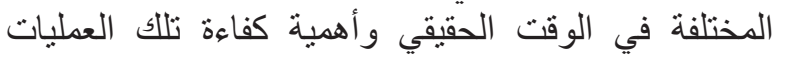

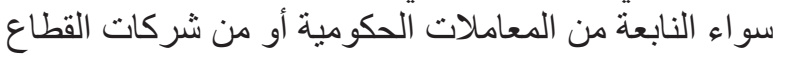

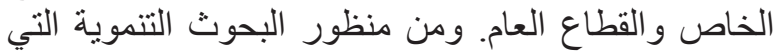

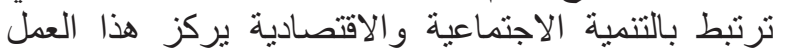

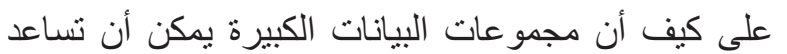

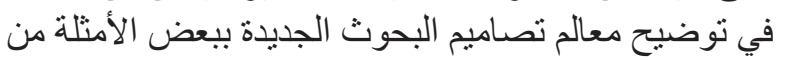

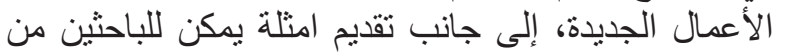

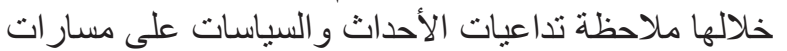

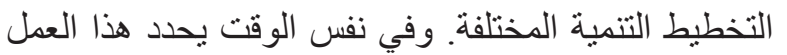

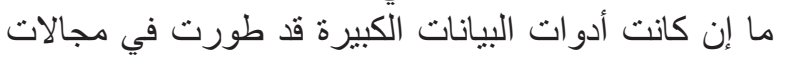
الإحصاء و علم الحاسب الآلي كالتعلم الاحصائي وأساتي أساليب تنقيب البيانات بهدف إيجاد التطبيقات الملائمة للتخطيط التهائ

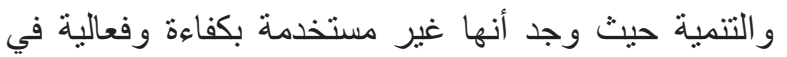
كثير من الأعمال سواء المتعلقة بمنظمات وشركات القئ القطاع

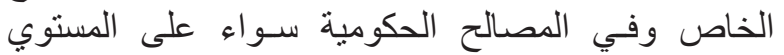

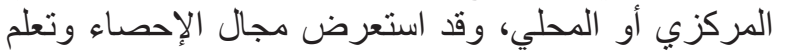
الالة المرتبطة بالأكاء الاصطي، وقاعي من حيث تحديد المفاهيم و الأنو اع و الألجوريثمات و والأكاء الأنماذج.

وفي نفس الوقت يناقش هذا العمل بعض التحديات الجديدة

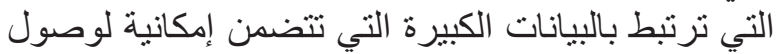


تحديد أبعاد خو اص البيانات الكبيرة في المعالم التالية: ب ا 1/ تو افر البيانات في الوقت الحقيقي: تعتبر القدرة علي التقاط ومعالجة البيانات في الوقت الحقات الحقيقي

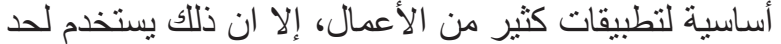

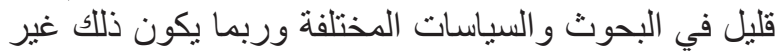

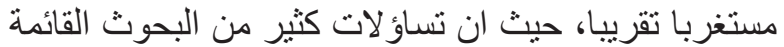

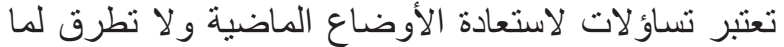

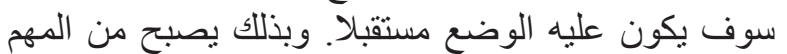
أكثر للبيانات أن تفصل وتصبح الوضع دقيقة بدلا من تو افر ها فوريا.

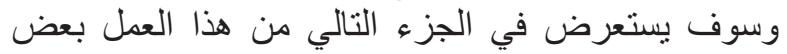
الطرق التي تبرهن فيها بيانات في الوقت الحتب الحقيقي التي تفيد البحوث المرتبطة بالسياسات وتخطيط أبعاد التنمية.

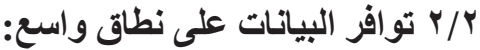

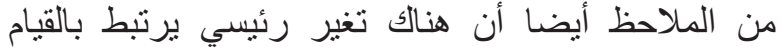

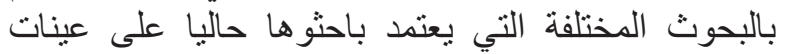

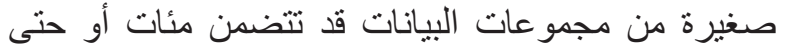

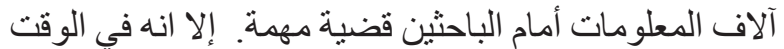

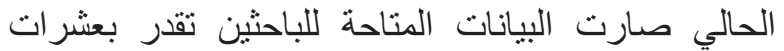

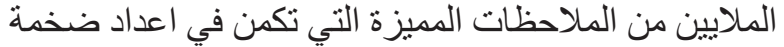

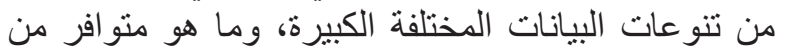

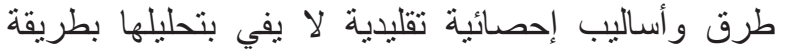

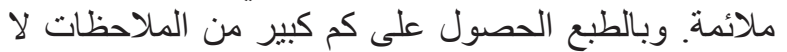

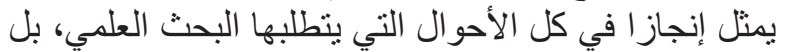

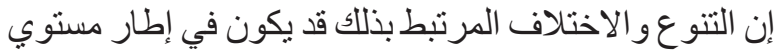

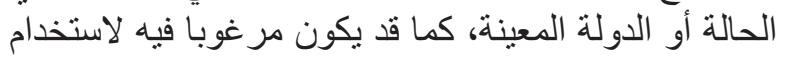

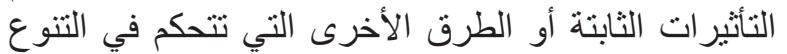
و عدم الانسجام إلا أنها تقلل أيضا القوة الإحسائية الإنية.

، r/ ت توافر البيانات عن أنواع متغيرات جديدة:

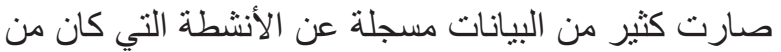

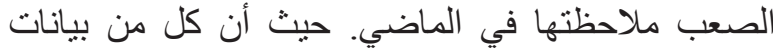
رسائل البريد الإلكتروني، أو بيانات المو اقع الجغر افية التي التي

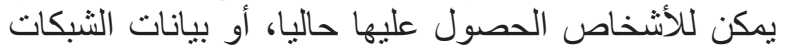

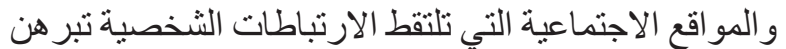
جيدا أنها تمثل فرصا سانحة وجيدة الإيدة للباحثين في مجالات العلوم الاجتماعية المختلفة. وكثير من الباحثين يتفقون على لإنى

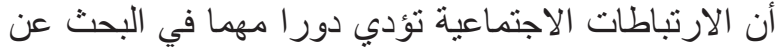

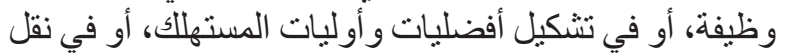
المعلومات وتر اسلها.

\section{r/ / ورود البيانات بهيكلية أقل:}

إحدى تداعيات توسع مجال المعلومات المسجلة ترتبط بمجموعات البيانات الجديدة التي تثتنمل على هيكلية أقل
مثلا. ومنذ عقود قلليلة مضت، كانت محلات تجارة التجزئة

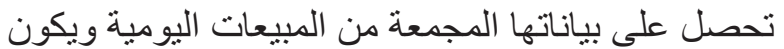

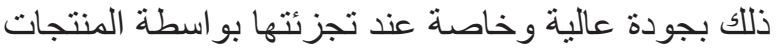

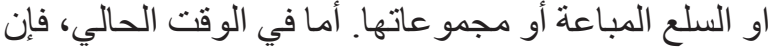

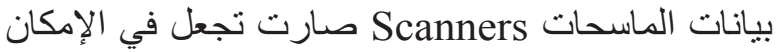

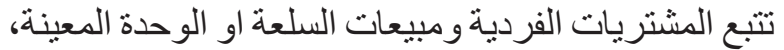
كما تلتقط في الوقت الحقيقي الذي تحدث التئ فيه و اقعة الثراء الثراء

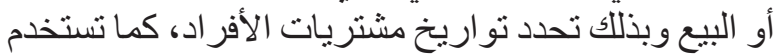

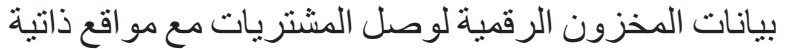

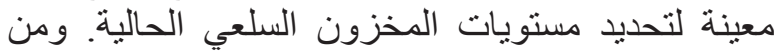

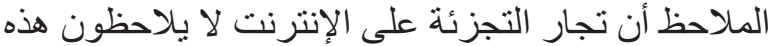

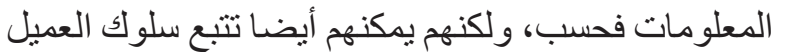

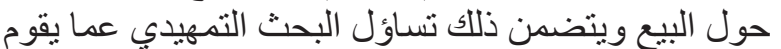

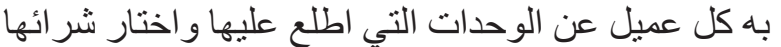

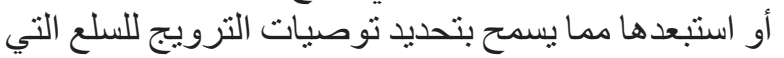

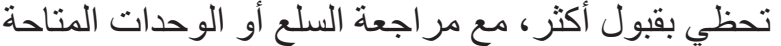

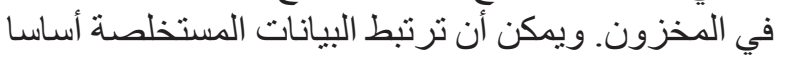

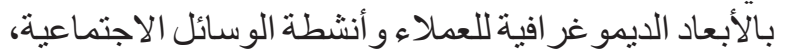

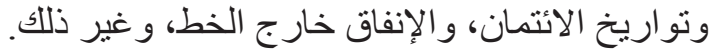
وفي نفس الوقت، صار يتو اجد أيضا تطور منو ازي الإي يتمثل في نشاط شركات الأعمال المختلفة التي حركت عمليخ الكاتياتها اليومية

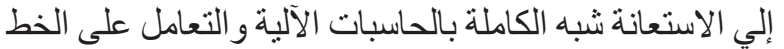

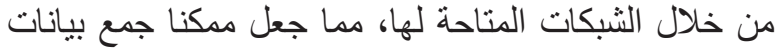

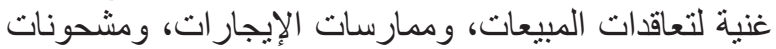

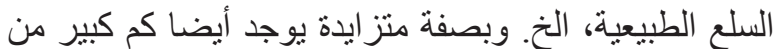

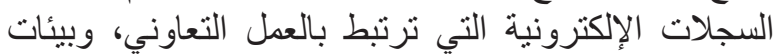

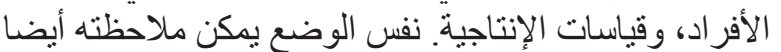

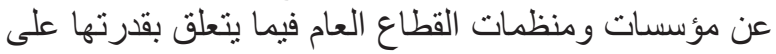

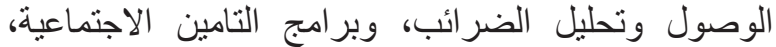

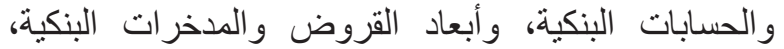
و المصروفات الحكومية والأنشطة التشريعية وغير ذلانك.

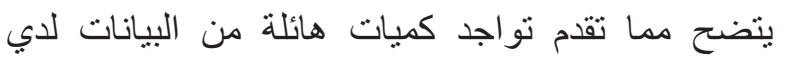

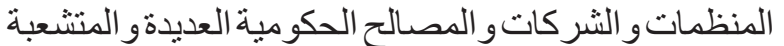

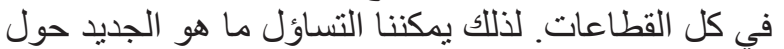

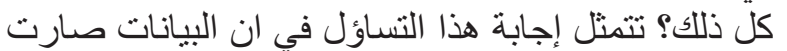

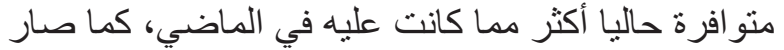

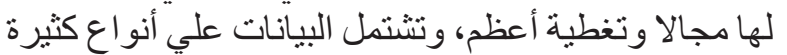

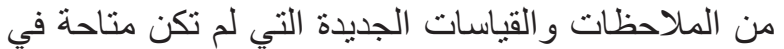

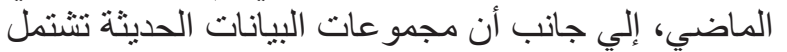
علي هيكلية قليلة جدا وفي بعض الأنيان الحيان تكون الهيكلية

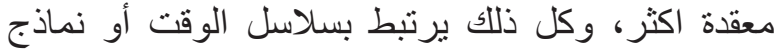

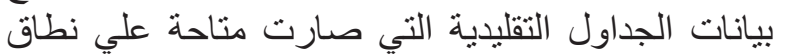
واسع أمام الباحثين في كثير من المجالات مما يسهم في نطي 
أوقات الويب الخاصة بها. وتحاول وظيفة شركة Apple الآلية بالكامل التنبؤ بباقي نص أو رسالة بريد إلخاص إلكتروني بناء

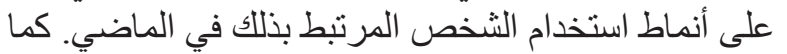

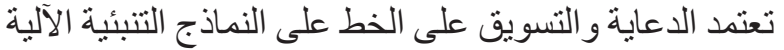
التي تستهدف الأفر اد المحتملين للاستجابة فيما يقدم لهم. لهاني

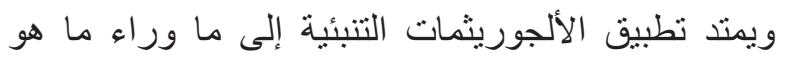

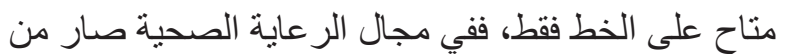

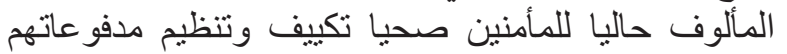

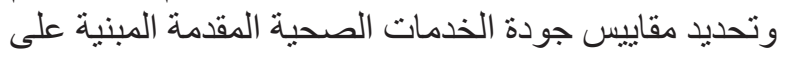

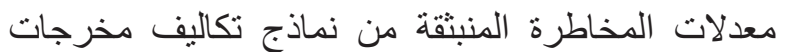

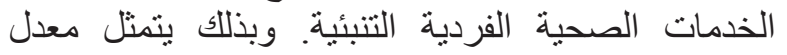
المخاطرة الفردية في التالي:

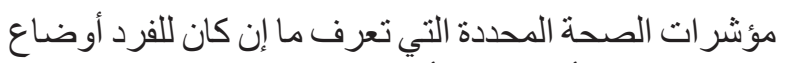
مرضية مزمنة أم لا، ومع أوز ان المؤشر ات المئ المختارة المبنية

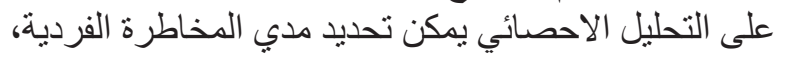

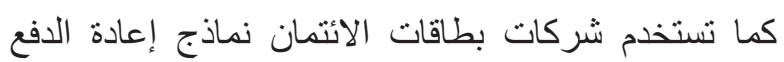
و التخلف لتوجيه أنشطة تسعير تها وتسويقها وتأمينها.

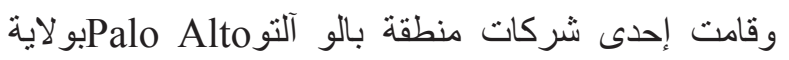

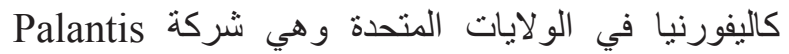
بتطوير ألجوريثمات تستخدم في التعرف الات على الإنى مخاطر

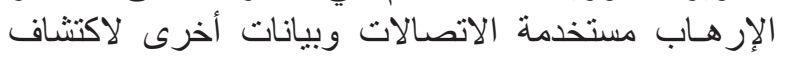

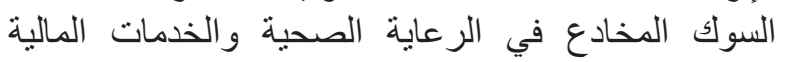
المختلفة مما در عليها مكاسب هائلة.

وفي إطار الممارسة الفعلية تعتمد هذه التطبيقات على تحلى تحويل

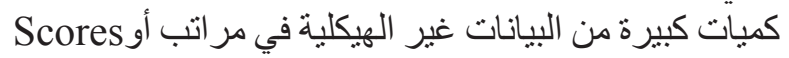

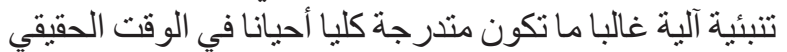
وبذلك يمكن استخدامها في طرق عديدة منها التنالي:

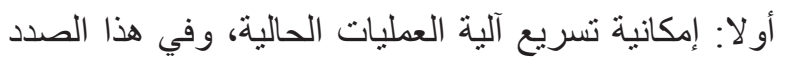
تضع شركة Amazon وحدات المطبو عات التي تنتبأ بتو افقها مع المستهلك أو في الوضع المعين، وبذللك تستبدل التوصية التي قد يكون الثخص حصل الثل عليها سابقا من أخصائي أو أولئ أمين المكتبة على سبيل المثنال.

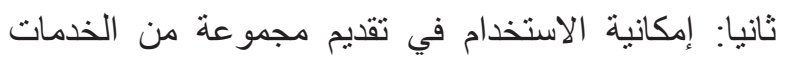

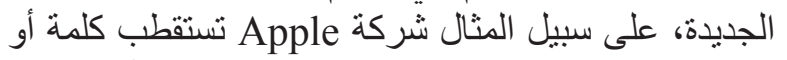

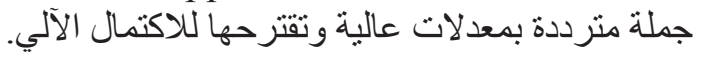

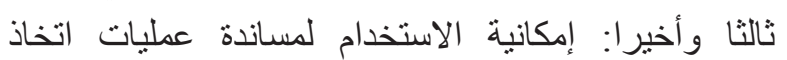

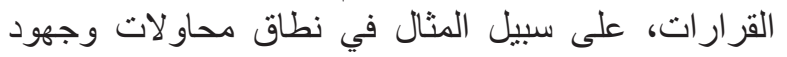

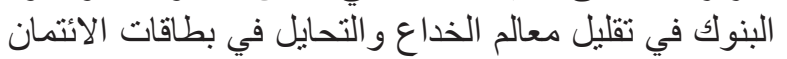

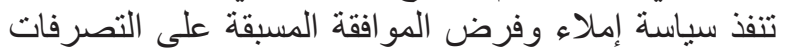

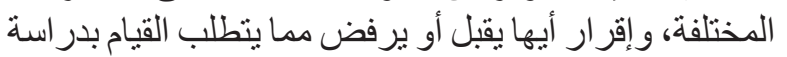
أكثر تعمقا بناء على معدلات التصرف أنصاف برف
وأبعاد أعلي. وفي مثنال تجارة التجزئة السابق الإشارة

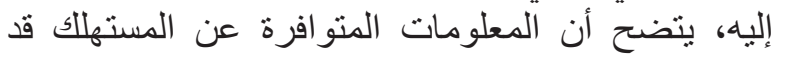

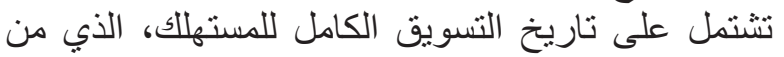

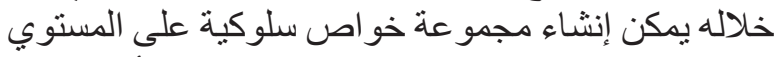

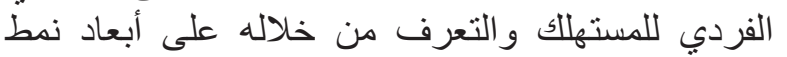

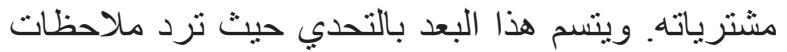

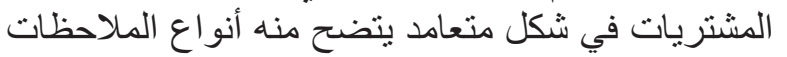

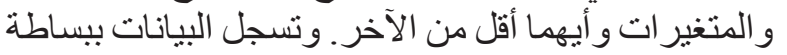

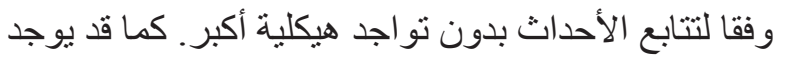

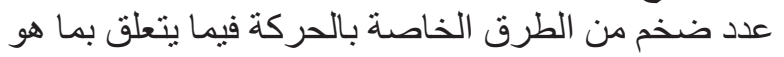

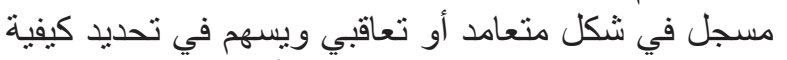

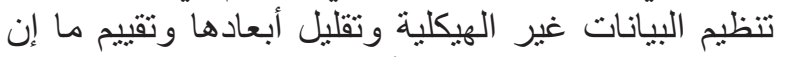

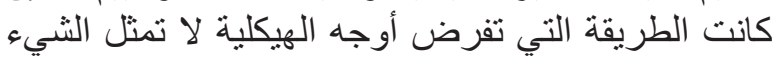
الذي يحصل عليه معظم الباحثين ومتخذي التهني القرارات

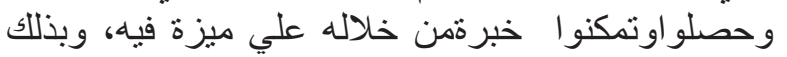

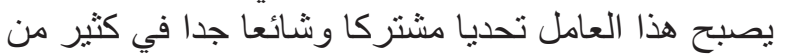
الدر اسات التطبيقية الهادفة.

ومن هذا المنطلق يمكن تطبيق نقطة شبيهة عند التفكير في

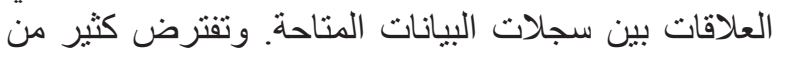
الطرق وخاصة المستخدمة في المجال الاحصات العنائي التقليدي

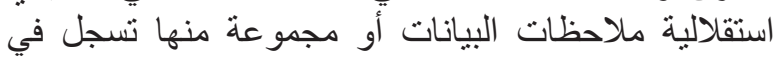

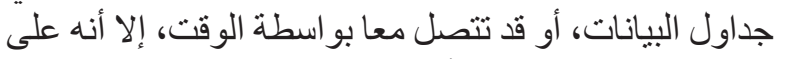

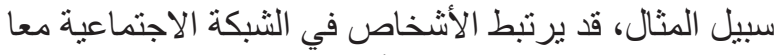

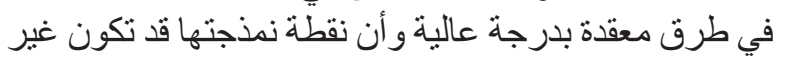

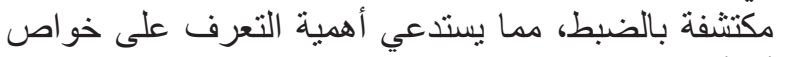

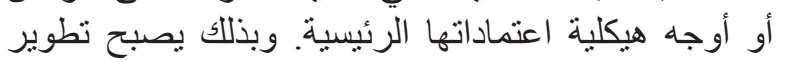
الطرق الملائمة للوضاع المختلفة اعلئي التي يو اجها محللو الأعمال

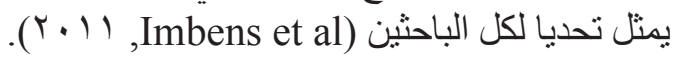
r. البيانات الكبيرة والنمنجة التنبئية:

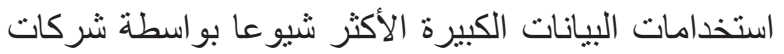

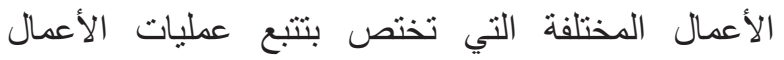
و المخرجات الناجمة منها بهدف بناء ترنيب واسع للنماذج التنبئية Predictive Models. وبينما تكون تحليلات الأعمال عملا رئيسيا وجوهريا لكفاءة وفعالية شركات

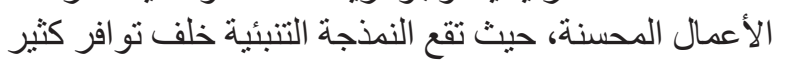
من المنتجات و الخدمات المعلوماتية المقدمة في السنة النئة الحديثة.

ومن الأمثلة المعينة لذلك و المألوفة للكثيرين ما برتبط بتوصيات كل من شركة Amazon وشركة NetFix التين تعتمدانعلى النماذج التنبئية لمشتريات الكتب ونت والأفيلام لكلا

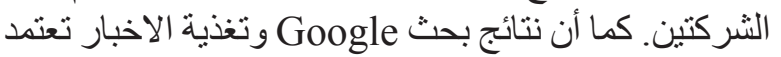
على الألجوريثمات التي تتنبأ بمدي نو افق صفحات أو مو اقع 
الذي تتو افر فيه متغير ات المخرج ويهدف لوصف كيف ترتبط

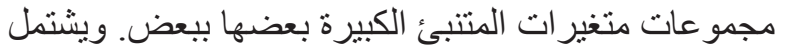

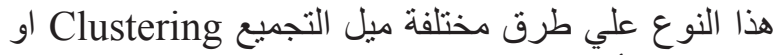

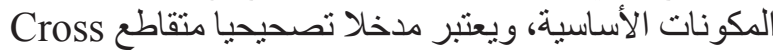
- Validation المتعلقة بالتخطبط و التنمية الاجتماعية و الاقتصادية.

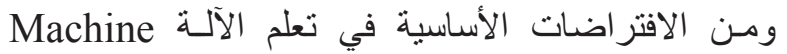

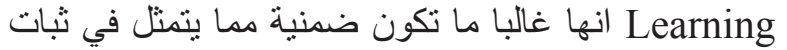

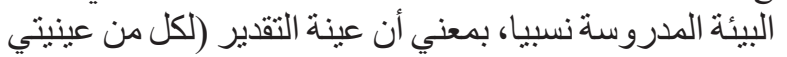
التدريب و الاختبار ) تكونا منتجنان بو اسطة نفس السحوبات المنات

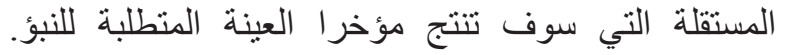

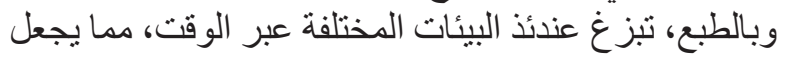

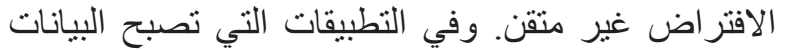

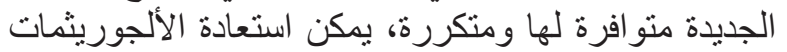

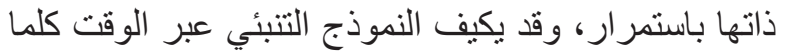
تغيرت البيئة المحيطة. وباعتبار كل من المخططين ومتخذي القرار ات فئه ور اسمي

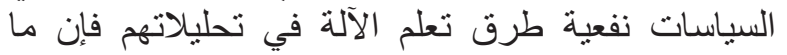

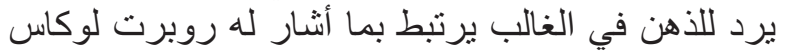
Robert Lucas

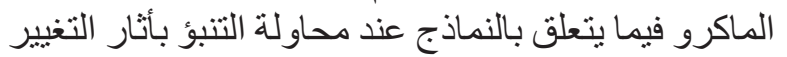

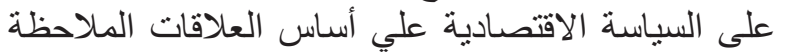

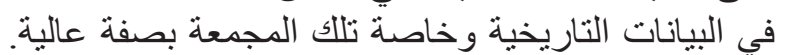

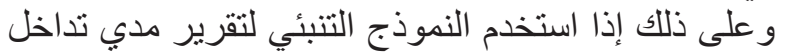

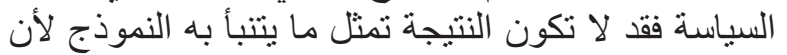

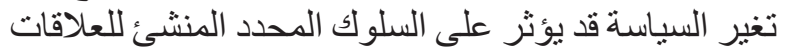

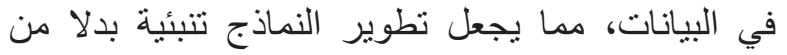

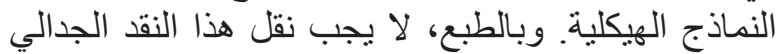

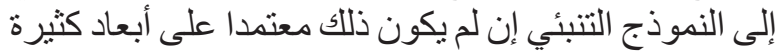

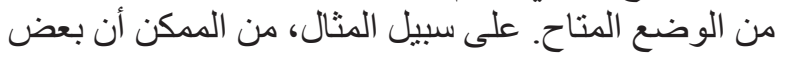

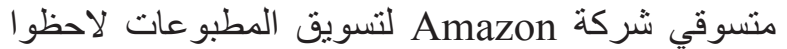

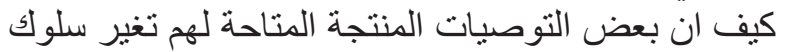

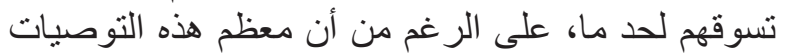

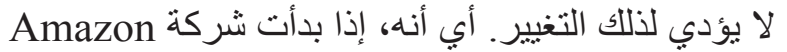

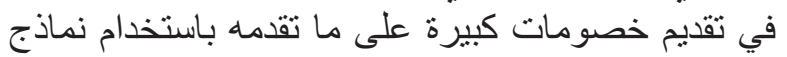
تنبئية شبيهة، فإنها سوف تستقطب تغيير سلوك كثير من فئن

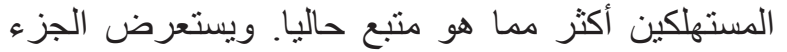
التالي أساليب الإحصاء وتعلم الآلة الموظفة فئل في التحليلات و و النمذجة التنبئية.

؛ ـ الإحصاء وتعلم الآلة:

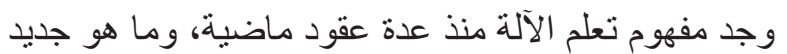
يرتبط بإمكانية تطبيق هذا المفهوم فيما يتعلق بكميات

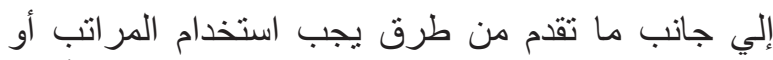
الدرجات التنبئية في التحليلات المؤداة، حيث يوجد التئ أيضا

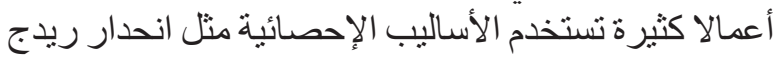
Ridge Regression

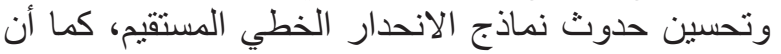
استخدام أسلوب Lasso الذي يمثل النموذج الخطي الذي الذي يقدر معامل الكثافة و التكاثر يعتبر مفيدا لتفضيل الحلول مع لفع لفي

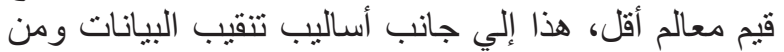
ضمنها ألجوريثمات تعلم الآلة Machine Learning في الب التي تحديد تلك الأعمال والتطبيقات التي منها نماذ التهاذج التصنيف

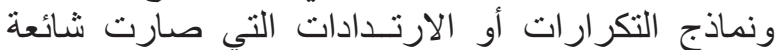

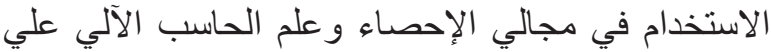

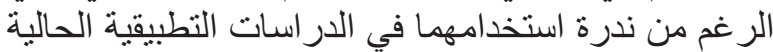

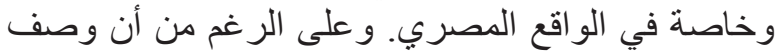
الطرق تفصيليا قد يمهذ الطريق وراء هذا الكرا العمل، إلا أننا

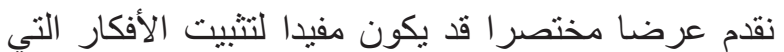
تتعلق بالمناقنتة اللاحقة. ومشكلة النمذجة التنبئية يمكن وصفها في تصور مجموعة من المداخل N التي ترنبط مع مجموعة منة منساوية من المقاييس المخرجة No بالإضافة لمجموعة أقلـل من من المتنبئات Predictors الأساسية Kن بالإسة وفي كثير من الحالات

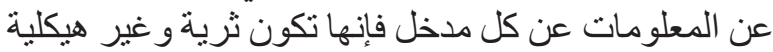

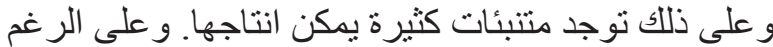

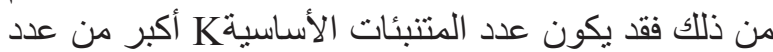
الملاحظات N مما يجعل الاهتمام الو اضح يرتبط بالتهيؤ

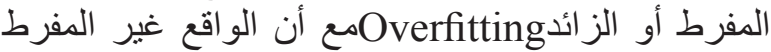
يتمثل في المعادلة التالي) مما يسهم في توضيح

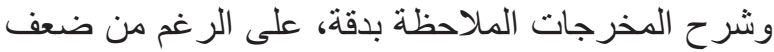

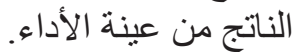

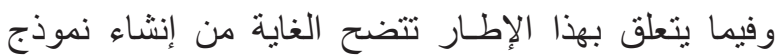
احصائي يعظم عينة القوة المتنبئ بها، إلإن انه في نفس الإنس

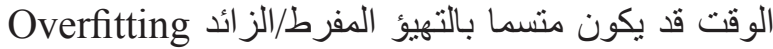
في الطريقة التي قد تقود لضعف أداء العينة. وتنتنوع الطرق

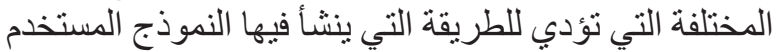

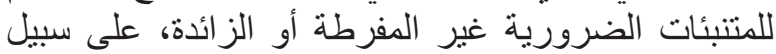
المثال طريقة Lasso التي يختار فيها معامل القيم المطلقة الذية Absolute Values Coefficient لتقييم التناوب بين عينة القوة التنبئية و التهيؤ المفرط/الز ائد

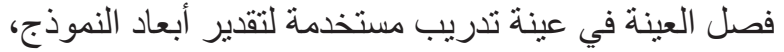

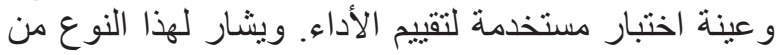
النمذجة التنبئية بالتعلم المر اقب Supervised Learning. ويوجد أيضا فصل كبير لأساليب البيانات الكبيرة التي يطلق

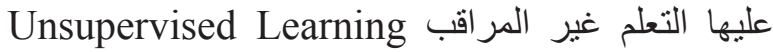


المنظمة المعينة تحسن الأداء أم لا، مما قد يؤدي للنظر

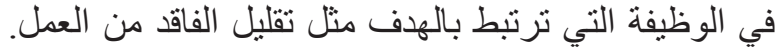

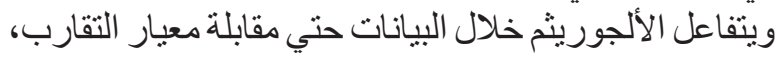

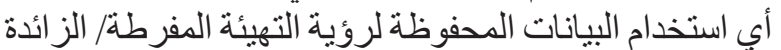

.Overfitting ك/ أنواع ألجوريثمات تعلم الآلة:

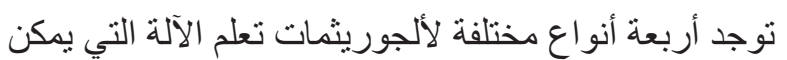

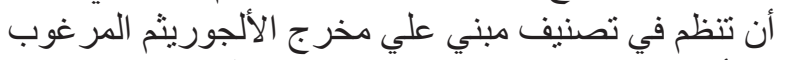

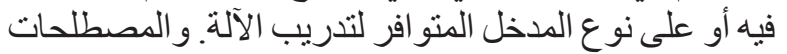

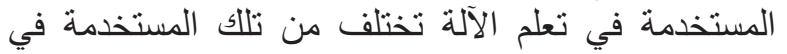
الإحصاء. على سبيل المثال، في تعلم الآلة يطلق على فلى الهدف

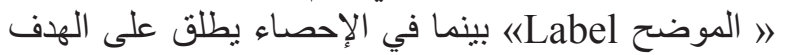

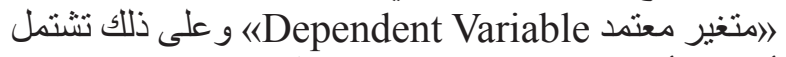
أنو اع الألجوريثمات الرئيسية لتعلم الآلة علي ما يلي:

Supervised Learning التعلم المر اقب الجوريمات

التعلم غير المر اقب Unsupervised Learning

Semisupervvised Learning التعلم شبه المر اقب البر

Reinforcement Learning تعلم التقوية/التعزيز و العرض التالي يشرح كل من هذه الأنواع الرئيسية:

\section{ع/ץ/ التعلم المراقب}

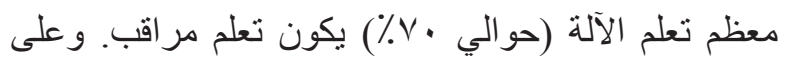

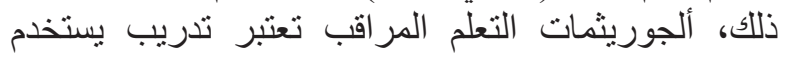

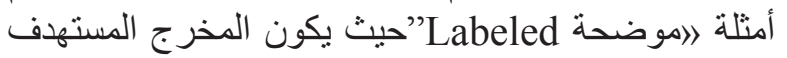

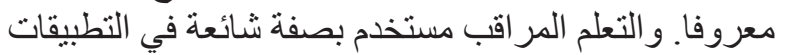

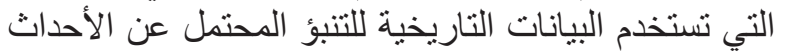

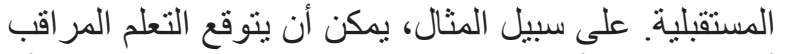

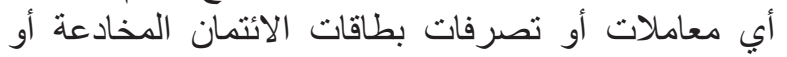

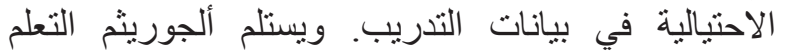

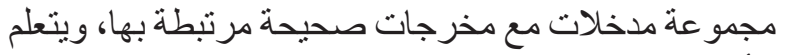
الألجوريثم بو اسطة مقارنة مخرجه الفئه الفعلي مع المخرجات

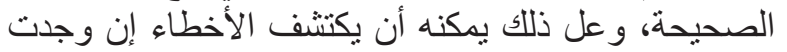
ويعدل النموذج طبقا لذلك. ويطلق علي المدخلات الالأوجها Features Fraud

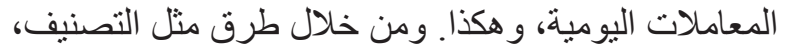

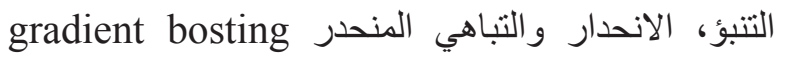
يستخدم تعلم الآلة المدخلات للتنبؤ بقيم المدخلات الموضحة

Labels

وفي هذه الحالة يمكن تطبيق نموذج حالات جديدة لتصنيف

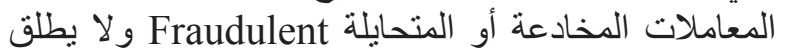

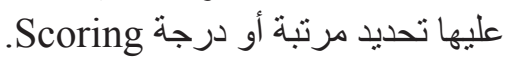

ضخمة من البيانات. وقد زاد الاهنمام في نظم تعلم الآلة

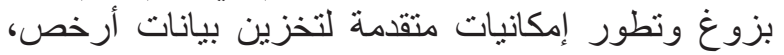

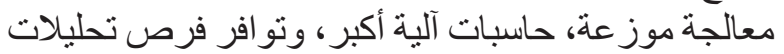
البيانات الكبيرة حاليا. ع / انفسير المصطلحات المستخدمة:

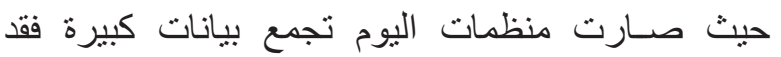

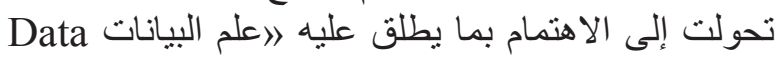
\$Science ومعني لها. ويتضدن ويبني علم البيانات على أساليب

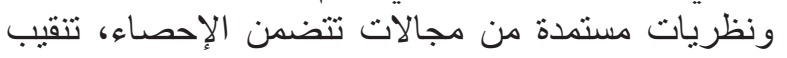

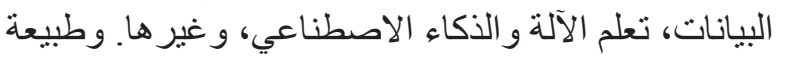

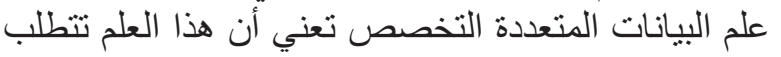

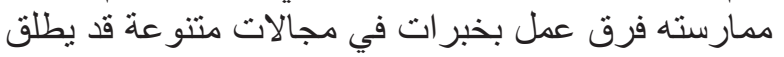
عليهم علماء البيانات.

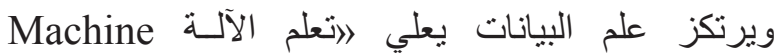

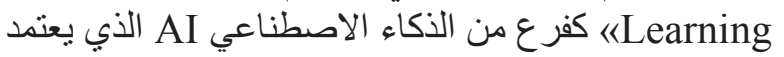

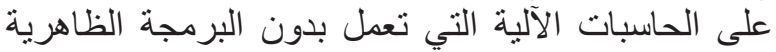

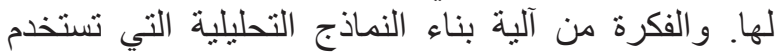

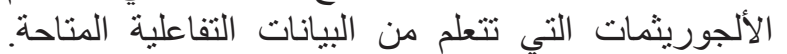
وبواسطة اختيار نموذج أحسن، يمكن تحسين النتائج عبر

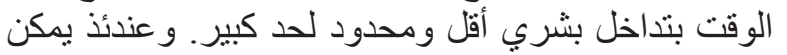

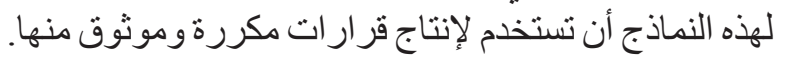
مما تقدم يمكن شرح أسلوب تعلم الآلة المرنكز على لإنى إنشاء

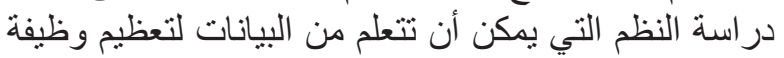

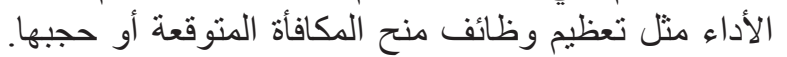

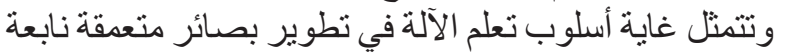

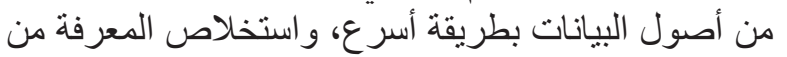
البيانات بدقة أعظٌ، وتقليل المخاطر بقدر الإمكان.

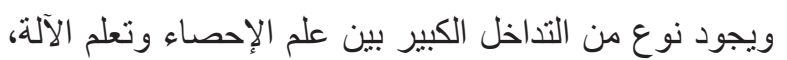

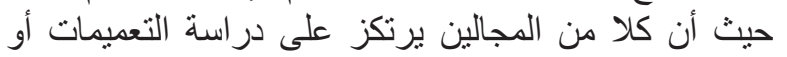

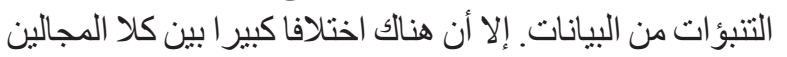

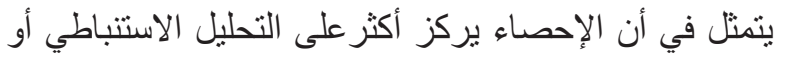

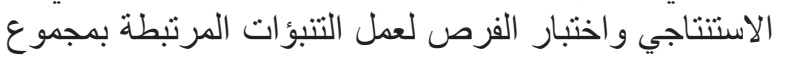

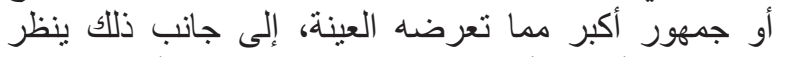
الإحصاء للأشياء كأبعاد التقدير ات، معدلات التهات الخطأ، افتر اضات التهات التوزيع و هكذا لفهم البيانات الطبيعية مع مكون عشو ائي.

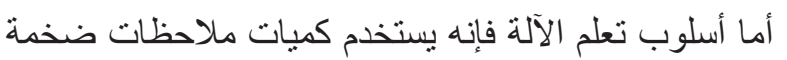

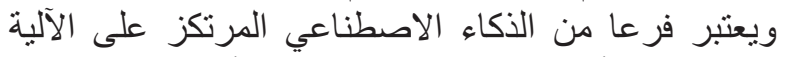
المرتبطة بالألجوريثمات التي تتداول الأشياء آليا كتحديد الأليد

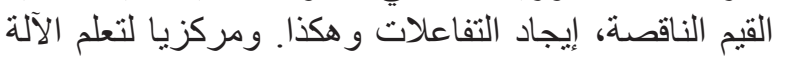

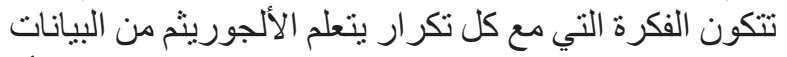

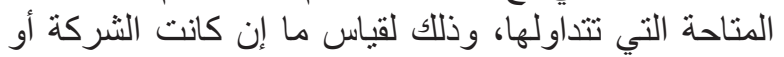


الألجوريثم إيجاد هيكل البيانات الأصلية. وفي هذه الحالة،

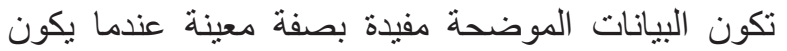

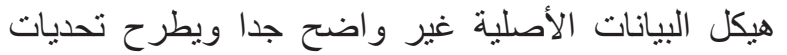

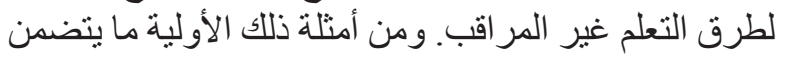
تحليل الأشكال Image Analysis (مثل تعريف وجنه أحد الأشخاص على الويب) والتحليل النصي Analysis وكتشاف المعرفة Knowledge Discovery ع/ץ/ ع تعلم التقوية/التعزيز: مع تعلم التقوية او التعزيز يكتشف الألجوريثم بنفسه أبي أفعال

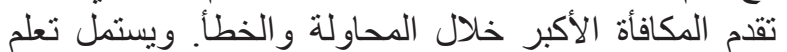
التقوية على ثلاثة مكونات رئيسية هي:

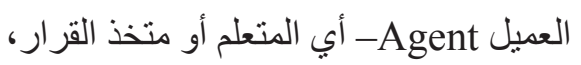
البيئة Environment- كل شيء يتعامل معه العميل، و و الأفعال Actions- ما يمكن أن يفعله العميل. ويهدف هذا النوع من التعلم أن يكون للعميل اختيار الأفعال

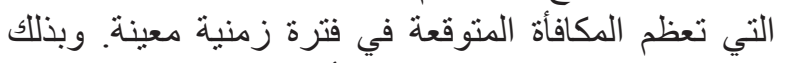

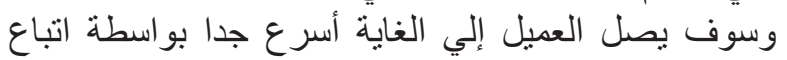
سياسة جيدة. و علي ذلك فإن الغاية في تعلم التقوية تكون التئ

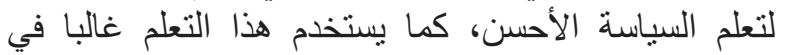
كل من مجالات علم الإنسان الآلي

.Navigation ولتعلم التقوية قوة ارتباطات مع الرقابة المثلي، الإحصاءات،

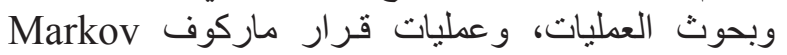
و (Decision Processes (MDPs

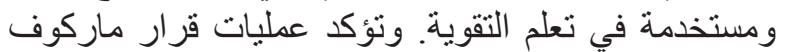
أن حالة البيئة تكون ملاحظة تماما بو اسطة العميل.

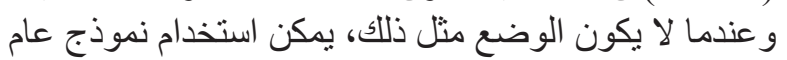
أكثر يطلق عليه عمليات قرار ماركوف لإن الممكن ملاحظتها لإيجاد السياسة التي تقوم بحل حالة عدم التأكد بينما تعظم

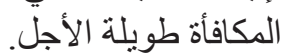

ع/ التعميم والتقييم واختيار النموذج: بغض النظر عن الطريقة المستخدمة، كل أنواع تعلم الآلة

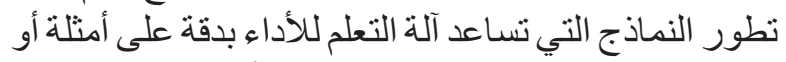

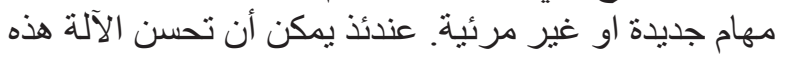

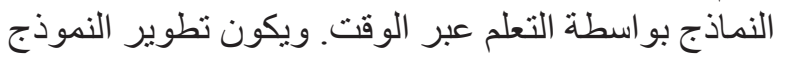

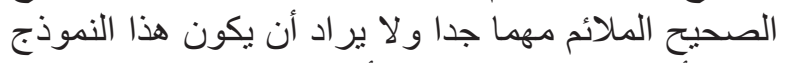
كبير أو صغير ا جدا ولكن أن يكون صحيحا. واشكل الشكل

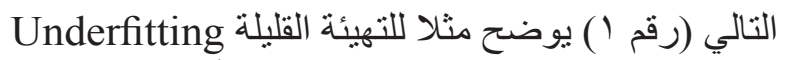

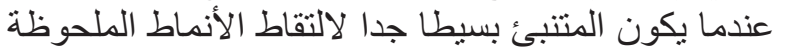
في البيانات، إلا أنه لا يكون جيدا لحل أمثلة المستقبل.

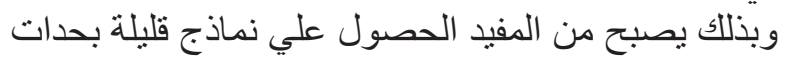

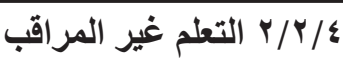

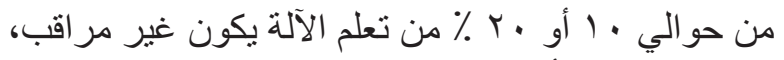

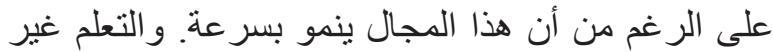

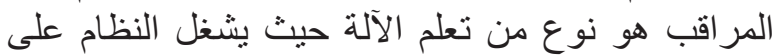

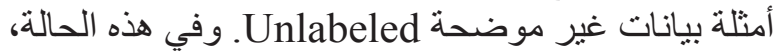
لا يخبر النظام الإجابة الصحيحة. ويحاول الألجوريثم إيجاد الهيكل الخفي أو المتتوع في البيانات غير الئه الموضحة.

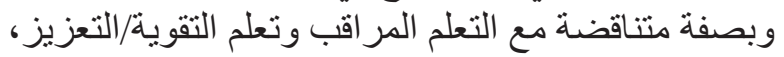

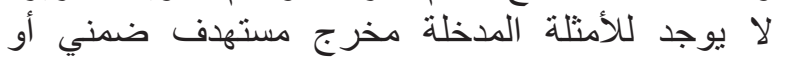
إثار ات مكافأة Reward ترتبط بكل مدخل، و وغاية التعلم

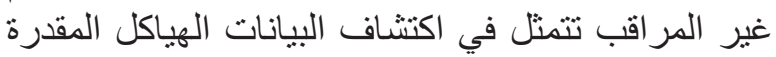
طبيعيا أي الأصلية في استخدام الطرق مثل التل التجميع العنقودي Clustering او تقليل البعد وبذللك يعمل التعليم غير المر اقب جيدا على بيانات المعاملات.

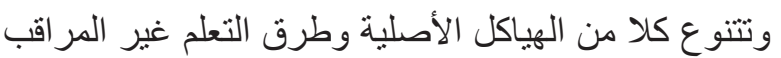

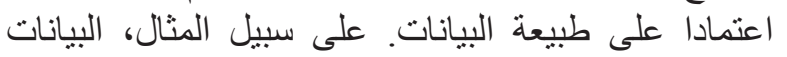

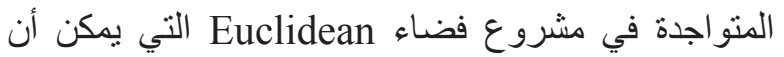
تكون قد نمذجت هيكليا بواسطة كثافة الاحتمال كما يمكنها

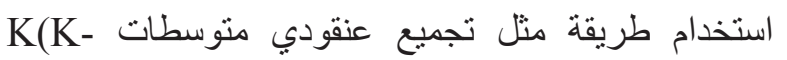

(means clustering

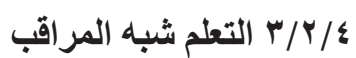

يستخدم التعلم شبه المراقب لنفس التبه التطبيقات في التعلم

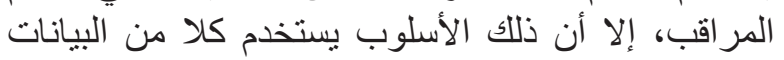

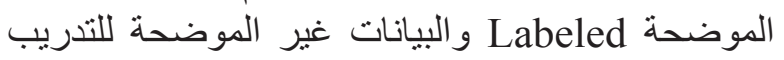

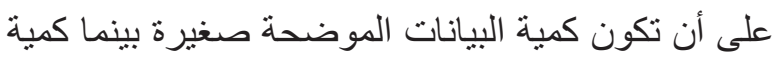

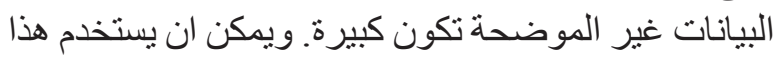

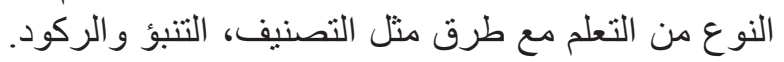
و التعلم شبه المر اقب بعتب طرنبر مفيدا عندما تكون التكلفة المرتبطة بالبيانات الموضحة عالية جدا لكي تسمح لعملية

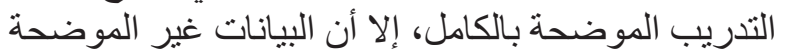

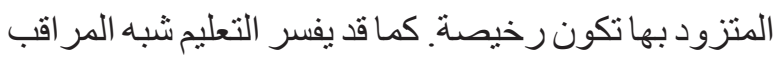

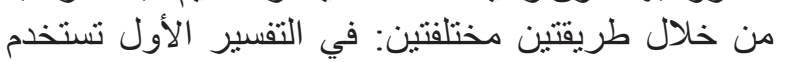

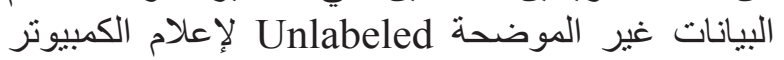

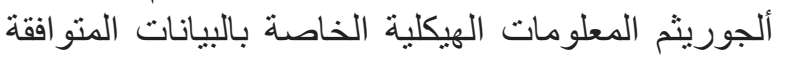

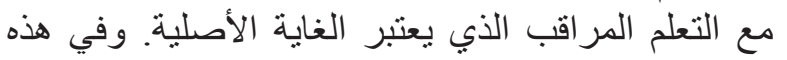

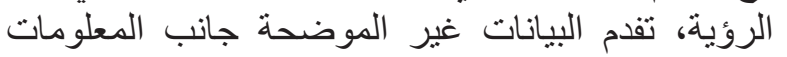

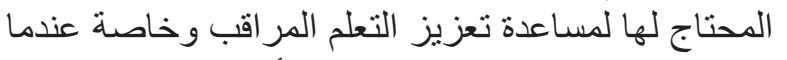

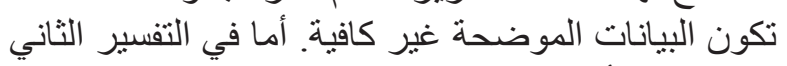
فإن الغاية الأصلية

تتمنل في التعلم غير المر اقب (التجميع العنقودي على سبيل

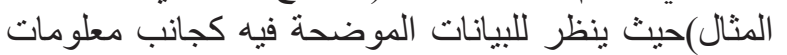
(مؤشرات عنقودية في حالة التجميع العنقودي) لمساعدة 
إلى أهمية التمعن في كل البيانات أو مجمو عاتها الفر عية لإنشاء

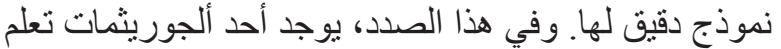

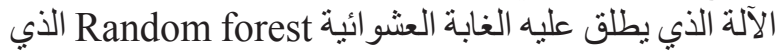

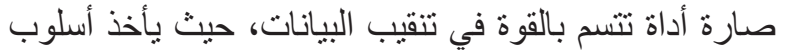

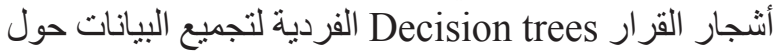

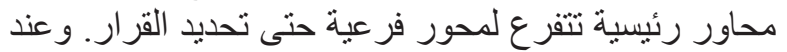

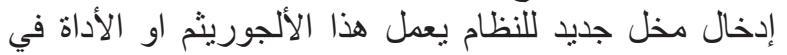

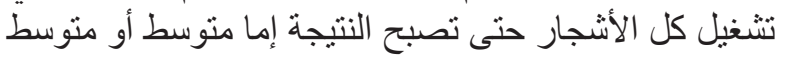
مرجح لكل المحاور الطرفية الموصلة. و على ذللك عند مواجهة إمكانية تهيئة تلك الغابة العشوائية

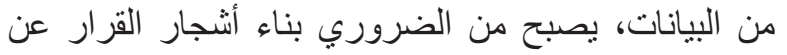

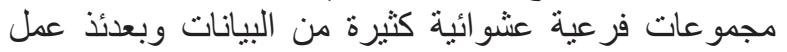

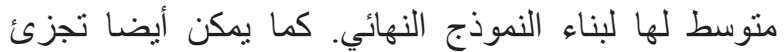
البيانات إلى متغيرات مختلفة في كل نقطة انشقات لناء لإنشاء

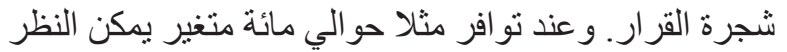

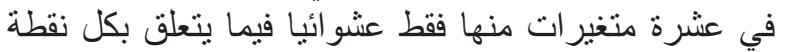

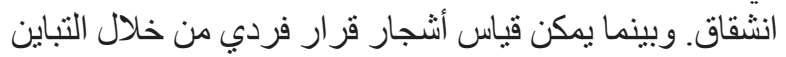

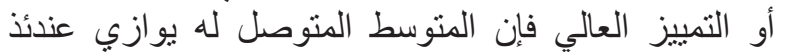

المتطرفين Extremes.

وفي هذه الحالة تسمح التكنولوجيات الجديدة منل التحليلات

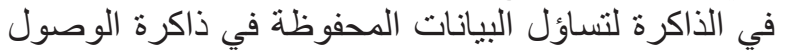
العشوائية RAM للحاسب الآلي و عبر البيئة الإلكترونية

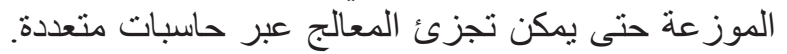

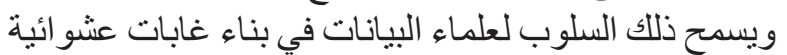
أسرع مما هو مناح. وفي استخدام نماذج تعلم الآلة في تطبيقات تنقيب بيانات

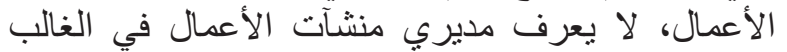

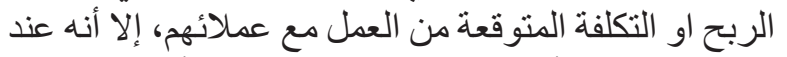
استخدام محرك أو منقب تتقيب بيانات المنشأة مثل محرك الته SAS Enterprise Miner

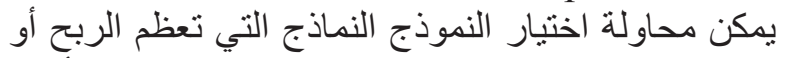

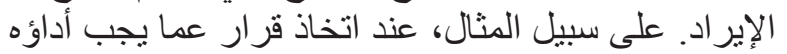

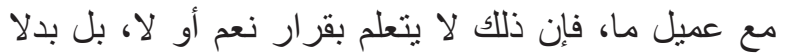

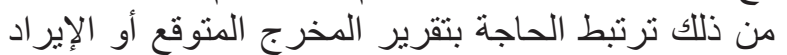

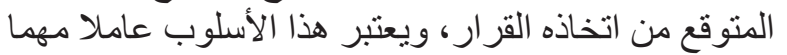

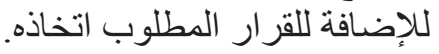

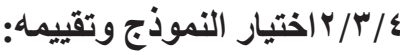

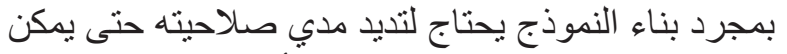

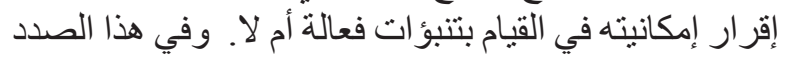

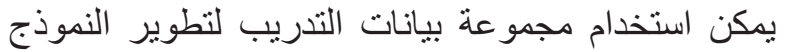

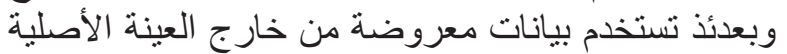

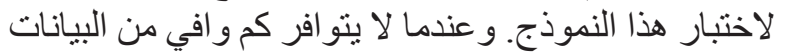

أو الفاظ محدودة جدا إلا أن ذلك النموذج لا يقوم بوظيفة

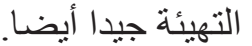

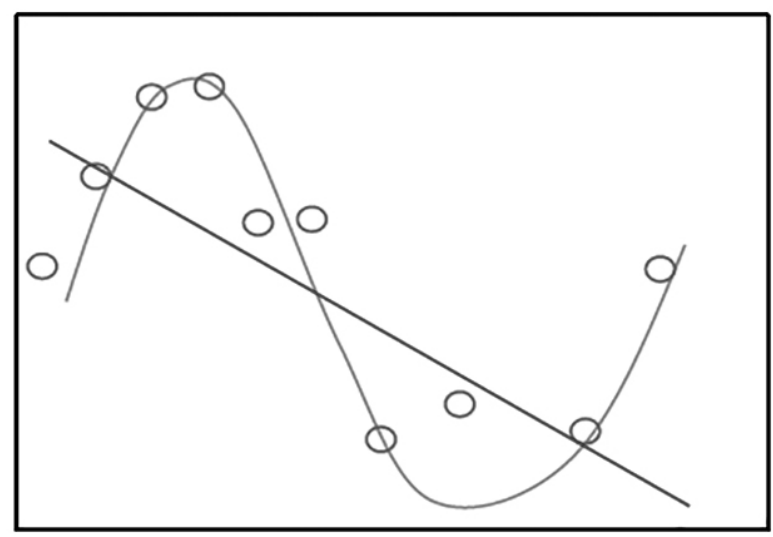

\section{Underfitting شكل (1) التهيئة القليلة}

أما اشكل التالي (Y) فإنه يبين التهيئة المفرطة أو الزائدة

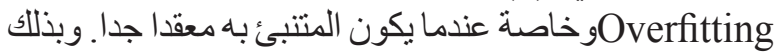
لا يعمم هذا النموذج أيضا عند محاولة تحديد مرنبة أو درجة الجنا Score

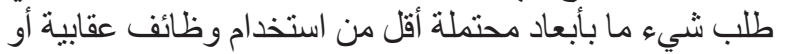

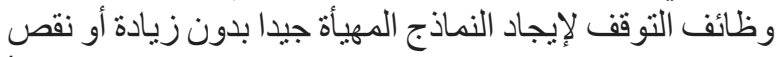

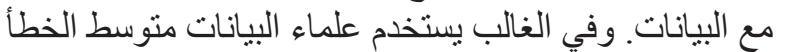
التربيعي أو غير المصنف لبيانات التوقف للقياس عندما يكون

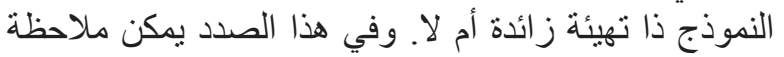

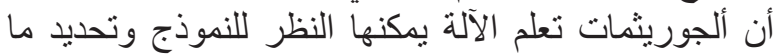
إن كانت المتغيرات تستخدم بكثرة حتي تقوم بتعديل النموذج

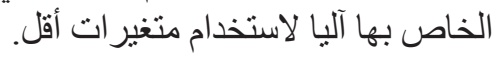

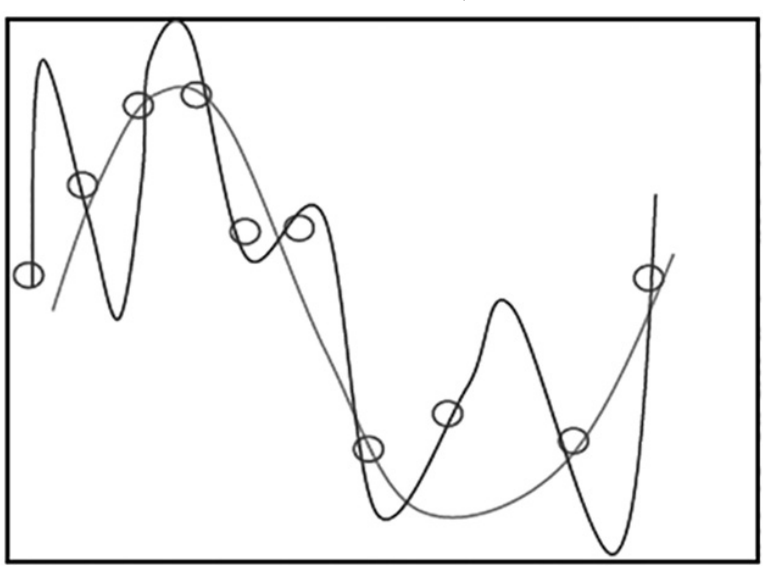

\section{Overfitting شكل (r) التهيئة المفرطة/الزائدة}

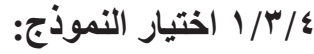

لبناء نموذج بحجم جيد يحتاج علماء البيانات تقليل درجة التعقيد التباء و الحجم الكبير لبيانات ذلك النموذج. وبذلك يحتاج بناء النماذج 


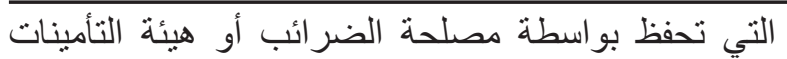

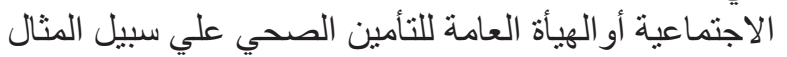

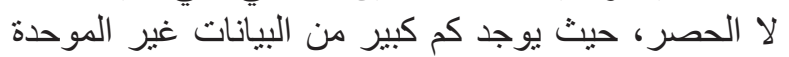

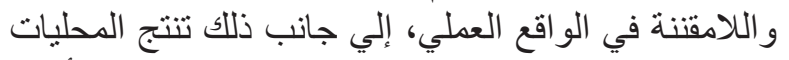

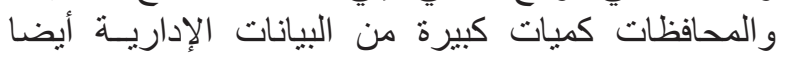

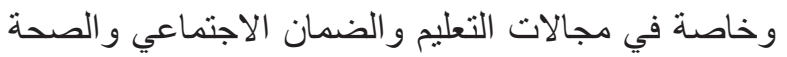

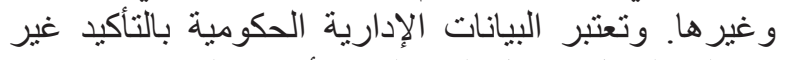

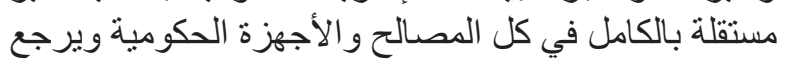
ذللك بسبب الوصول المحدود بل و الممنوع الاطلاع عليها

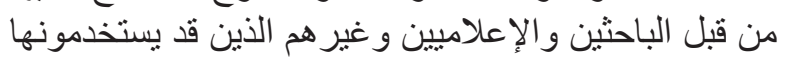
للكثف عن حقائق جديدة تفيد في جهود الإعنائ والتخطيط و التنمية.

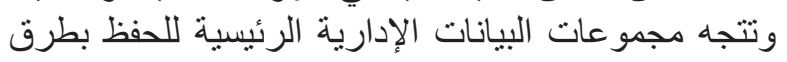

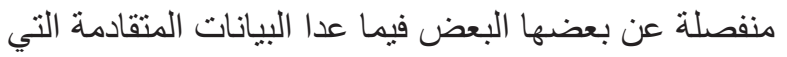

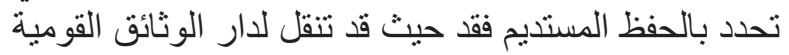

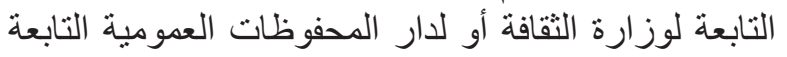

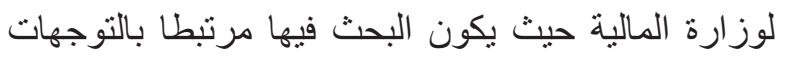

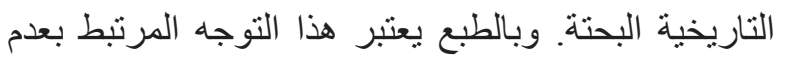

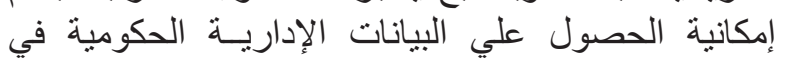

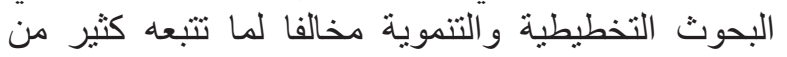
الدول المتقدمة كالدول الأوروبية علي سبيل المثنال التي التي تمتلك البيانات التي تمزج مجمول الأوروبة عات البيانات الديمو غر افية

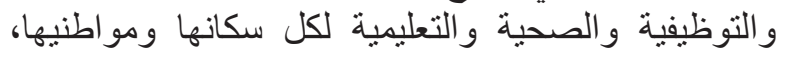

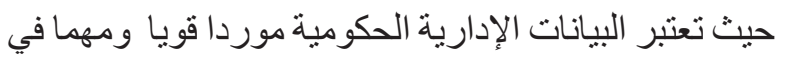

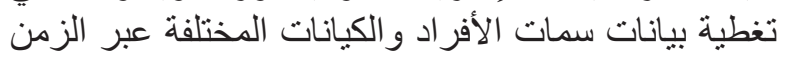

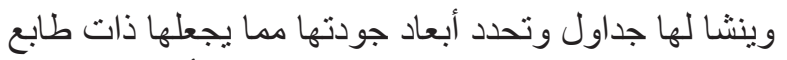
ثري لاستخلاص كثير من المؤشر ات ذات الأهمات الهمية للتخطبط

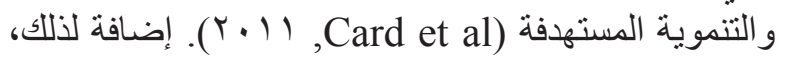

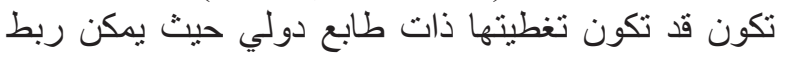

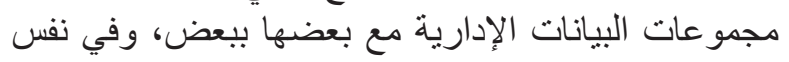

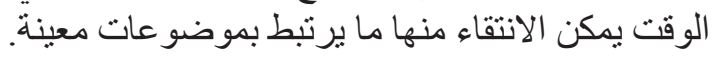
وفي بعض الحالات التي تسمح المصلحة الحكومية إمكانية

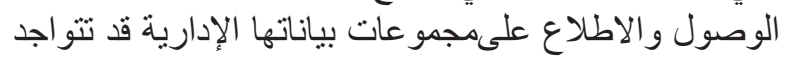

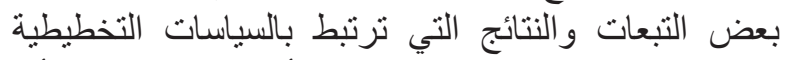

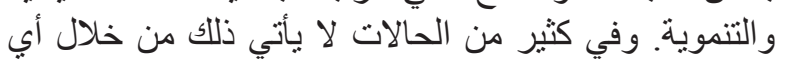

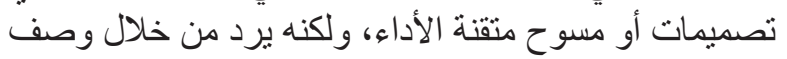

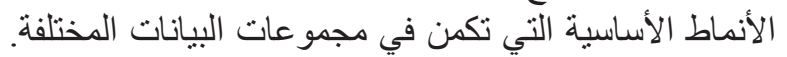

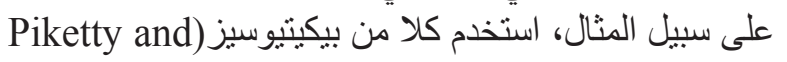

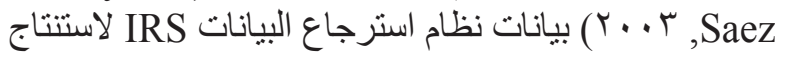

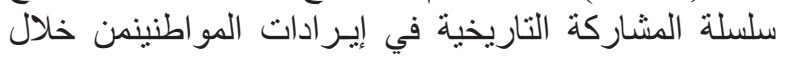

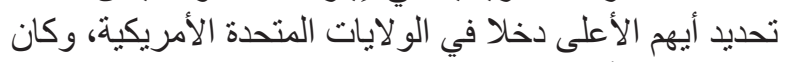

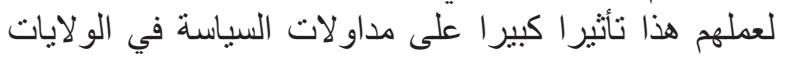

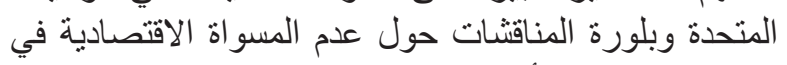
دخول المو اطنين الأمريكيين.
التي يسمح لبعضها الحفظ للاختيار ، تستخدم عينة فرعية أو كئون

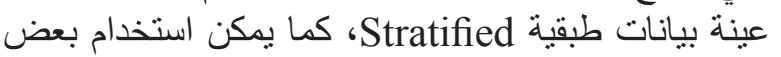

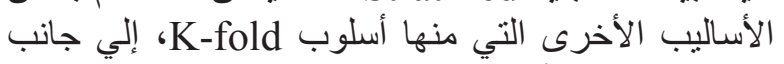

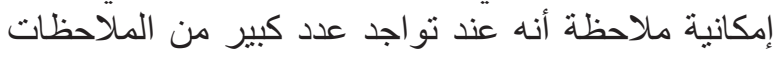

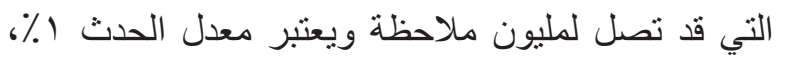

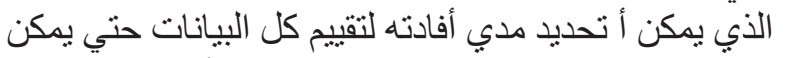

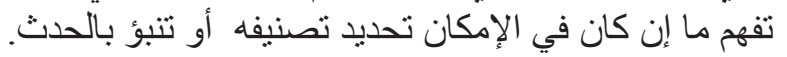

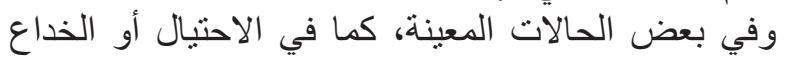
الذي يكون معدل الحدث فيه صغير ا، فإنه يمكن إيجاد الإنه عينة زائدة Oversample لتصحيح التحيز في مجمو عة البيانات إنهات الفرعية وتطوير عينات حبوية تضع نقات النيز أكبر إلي معدل الحدث مما يؤدي لنجاح النموذج أحسن. وقد طورت بعض النماذج لاستخدام قاعدة بيانات التسويق

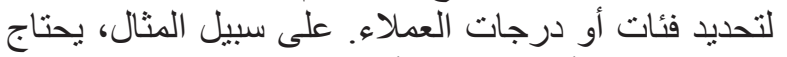

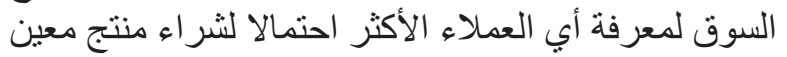

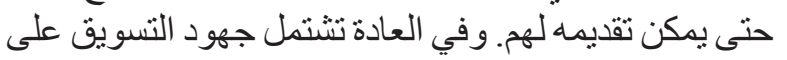
معدل حدث صغير بطلق عليه في العادة فئ معدل الاستجابة

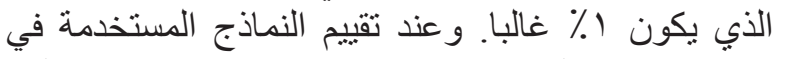

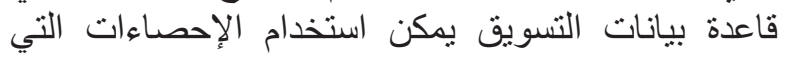

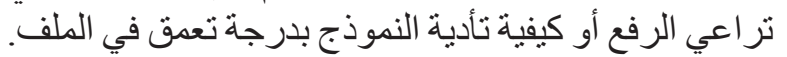

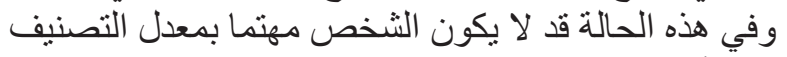

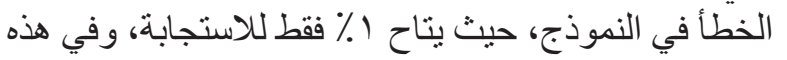

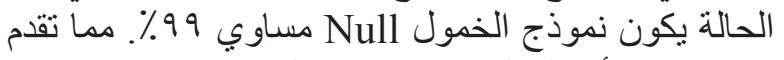
يصبح من الأفضل البداء في تطوير التنبؤات وإنشي إنشاء سماتها التي تتعلق بالرفع واختيار النماذج التي تعظم عملية الرفع في الملف.

•ـ الفرص التي تتيحها البيانات الكبيرة للسياسات التخطيطية والتنموية: - و الفرصية

استخدامات البيانات الكبيرة الأساسية للسياسات التخطيطية

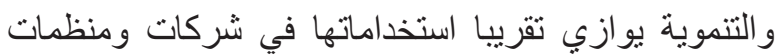

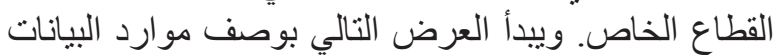

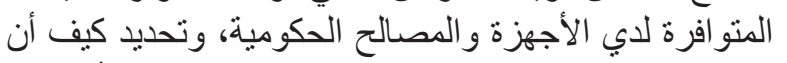

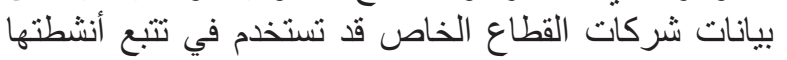

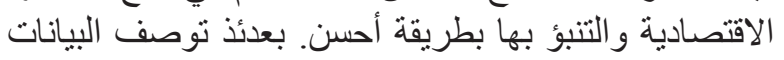
الكبيرة المستخدمة لإعلام قر ار ات السياسة أو لتحسين الخدمات

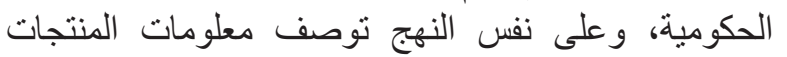
و الخدمات المتوصل لها.

1/ استخدامات البيانات الإدارية الحكومية:

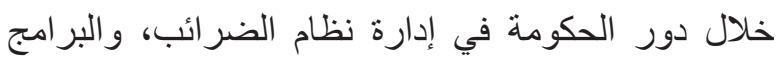

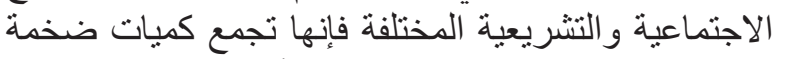

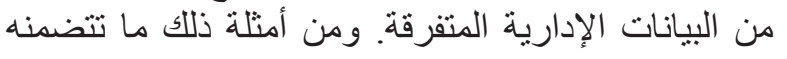
مجموعات بيانات المستويات التنفيذية الدنيا الغنية تلك الكية 
البحوث الاقتصادية و التعرف علي بيانات تضخم التكرار

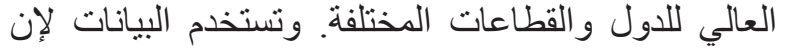
شاء كثافات الأسعار التي يمكن تحديثها في الوقات التهات الحقيقي.

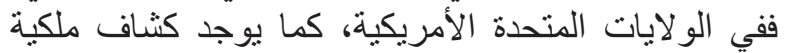
الأعمال الشخصية Business Personal Property (BPP) الذي يتبع كثاف سعر المستهلك (CPI) نسبيا. وفي الأني بعض الدول الأخرى قد لا تكون مقاييس المستح الحكومية

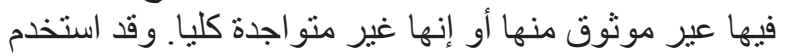

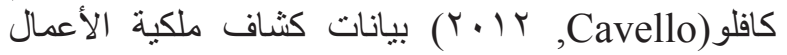
الثخصية (BPP) لتوثيق أنماط السعر بنفس الطريقة التي

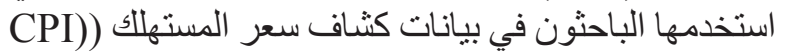

( \..人, (Klenow and Kryustov

وتوجد أيضا إمكانيات شبيهة تتعلق بزيادة قياس إنفاق

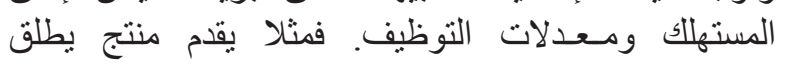
عليه "SpendingPulse" في سـوق بطاقات الائتمان MasterCard

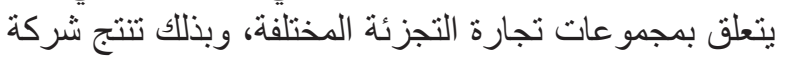

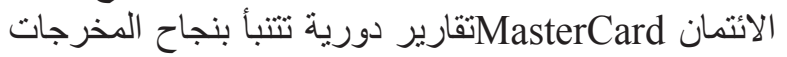
المبنية علي المسح للأمام في طليعة الوقت، لونان

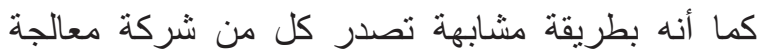
البيانات الآلية ADP(وهي شركة مقدمة للسحابة المبنية علي حلول إدارة رأس المال البشري وخدمات وخدمات تعهيد عملية

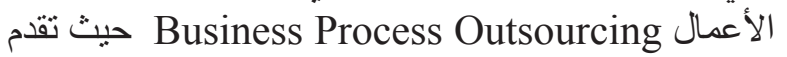

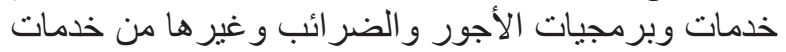

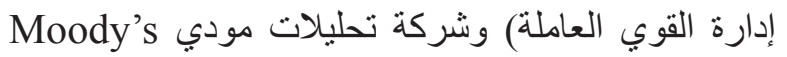

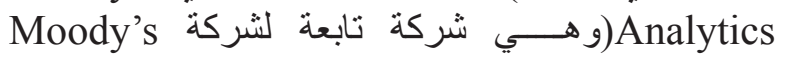
Corporation

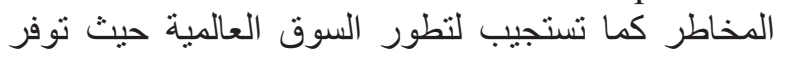

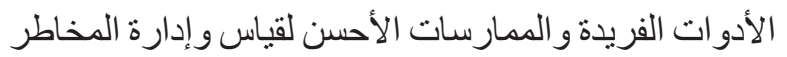

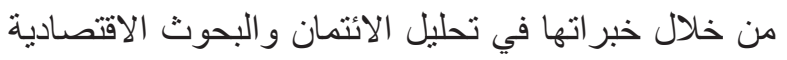

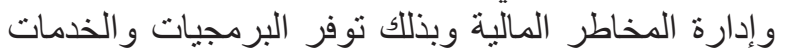

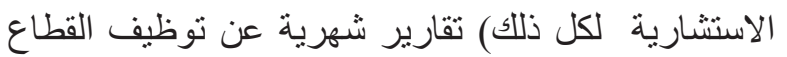

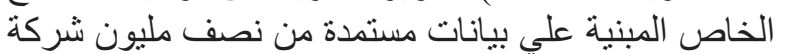

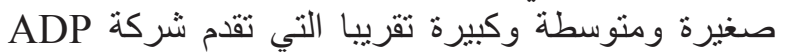

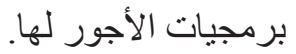
و على الر غم من تلك المداخل المرتبطة بالقياسات المختلفة،

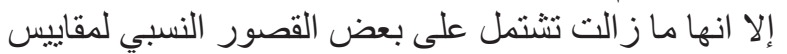

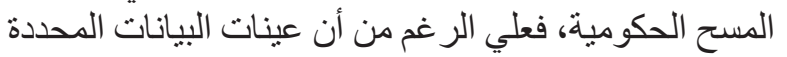

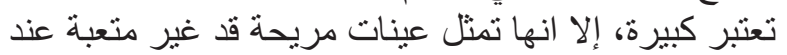

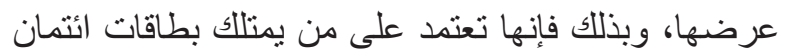

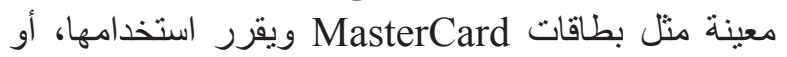

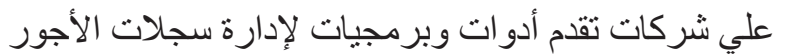

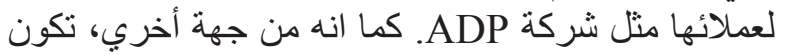

ومثنال آخر قد يختلف في التفاصيل عن المثنال السابق إلا

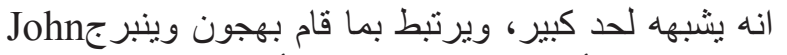
Wennberg للصحة و الأداء الكلينيكي لfartmouth Institute of Health and Clinical Practice وزملائه من الباحثين إلي تواجد تبيان غير مرغوب في فيه

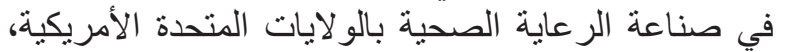

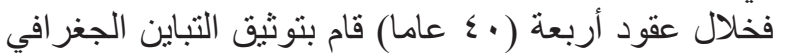

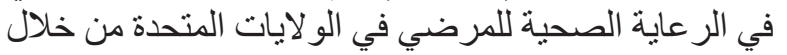

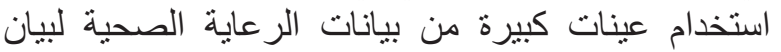

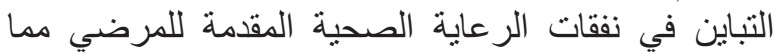

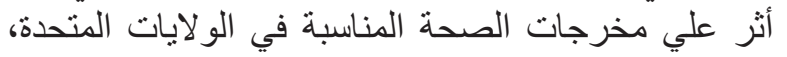

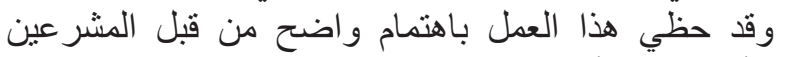

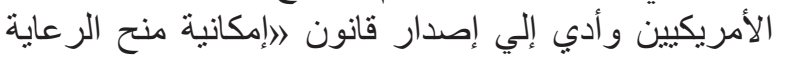

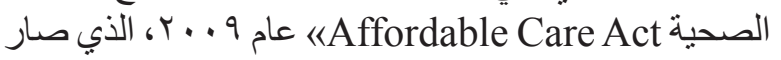
يمثل الدليل الرئيسي لعدم الكفاءة في نظام الرعاية الصحية بالو لايات المتحدة الأمريكية.

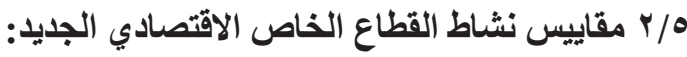

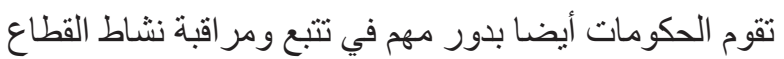

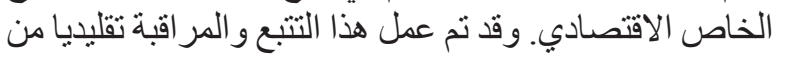

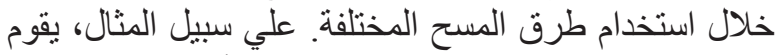

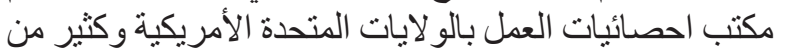

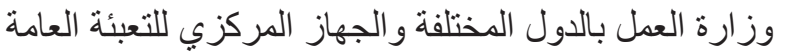

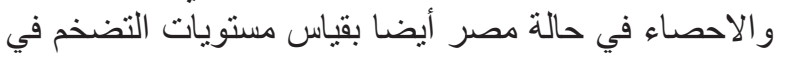

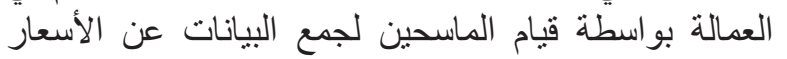

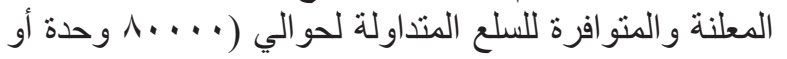

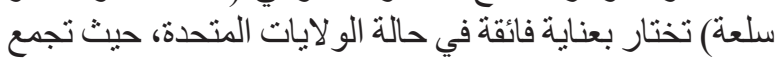

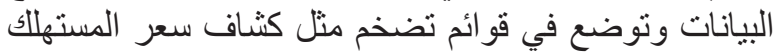
Consumer Price Index (CPI للتوظيف و الإسكان ومصروفات المستهللك و الأجور التي تعتمد علي طرق مسحية شبيهة. إلى جانب تللك النوعيات من المسوح نوجد مداخل بديلة

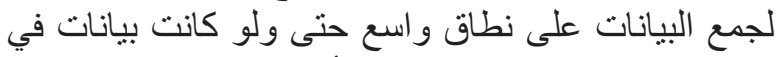

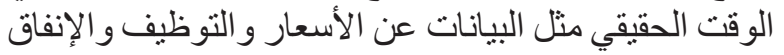

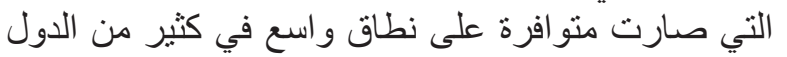

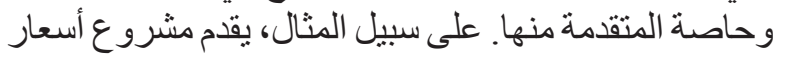

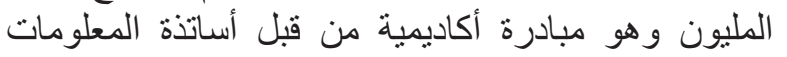

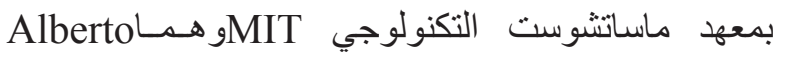
Carvalho and RoberoRigbon

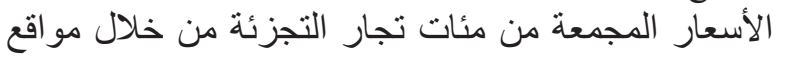

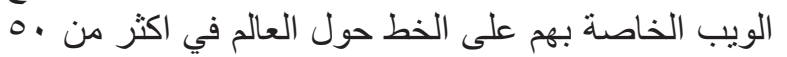

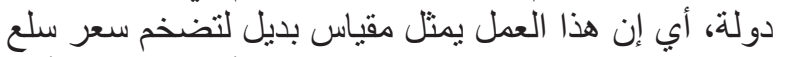
تجارة التجزئة، ويعتمد علي بيانات علي أساس يومي لألئ لأداء 
من التغييرات الكبيرة في الأعمال المعاصرة ما يتمثل في التداول و القرار ات الوتينية بو اسطة كميات تحليلات البيانات

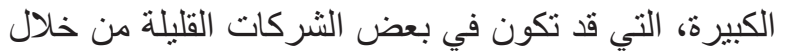

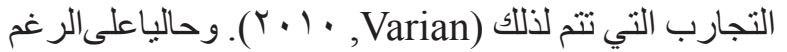

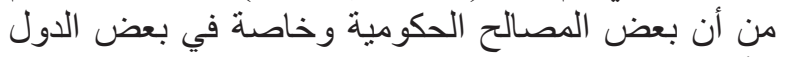

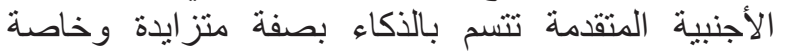
فيما يتصل باستخدام تحليلات البيانات لتحسين عملياتها

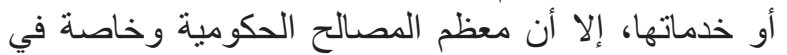

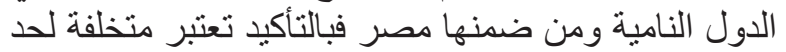
كبير عن شركات القطاع الخاص الأحسن بصفة خاصنة خاصة في استخدام تحليلات البيانات الكبيرة الناجمة من بئنة بياناتها الإداريـة الضخمة، كما انها تواجه كم كبير من التهات التحديات

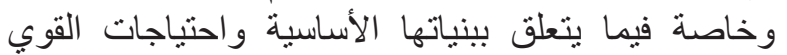

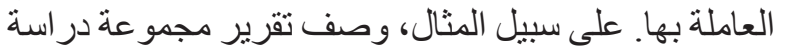

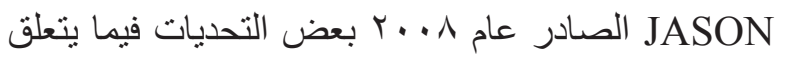

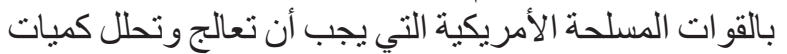

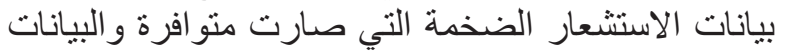

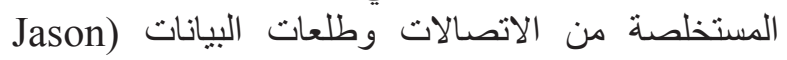

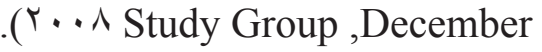
وفي بعض الأحيان، تجمع المصالح و الأجهزة الحكومية كم

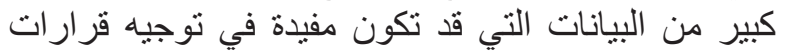

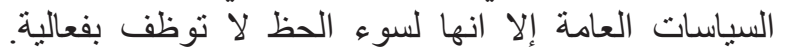

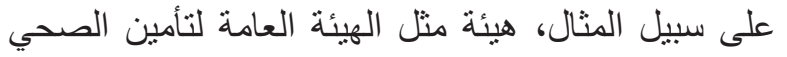

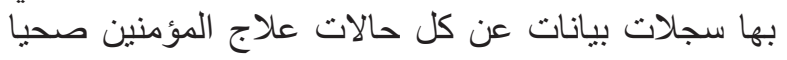
من موظفي الدولة وبذللك تمنلك كم ضخم من مجموعات البيانات الصحية التي تخص الحالات المرضية التي ترددت

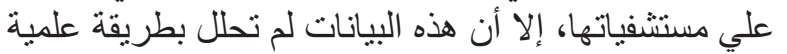

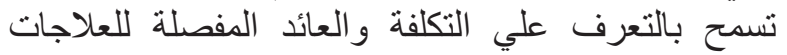

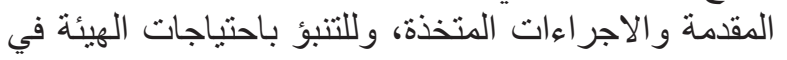

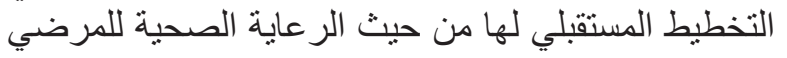
و علاجاتهم.

و علي ذلك يجب علي الهيئات و المصالح الحكومية المختلفة

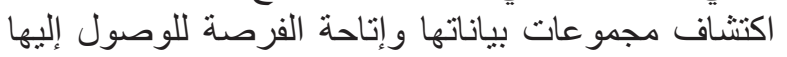
من قبل الباحثين و المخططين وراسمي السياسة سواء التهاء بالمنظمة أو من خار جها لكي يحللو ها بهدف تحسن تحسين عمليات الهيئة أو المصلحة ذاتها ورسم أبعاد خططها المستقبلية

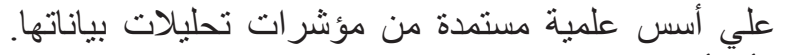

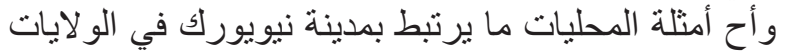

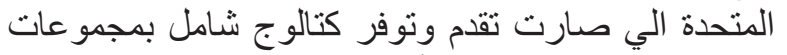

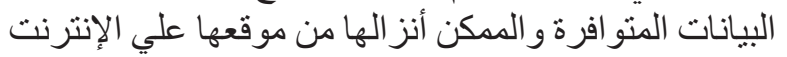

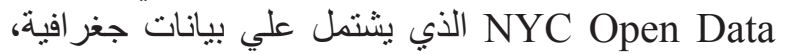

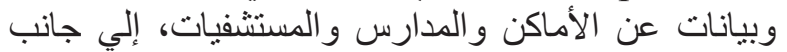

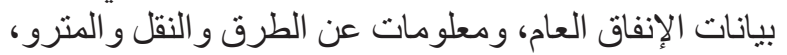

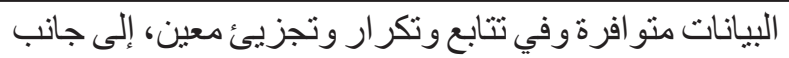

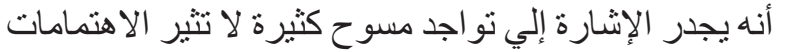

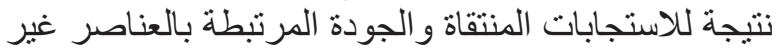

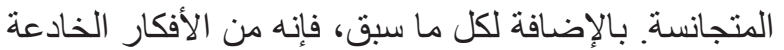

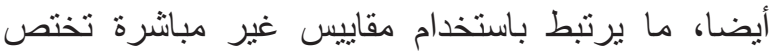

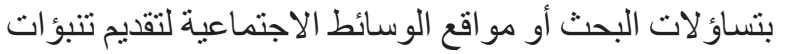

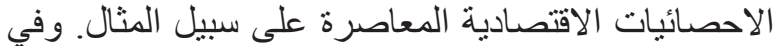

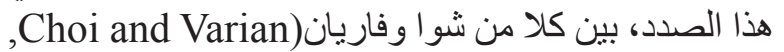

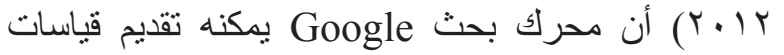
دقيقة ترتبط بسلسلة الوقت الاقتصادي تختص بط بطلبات

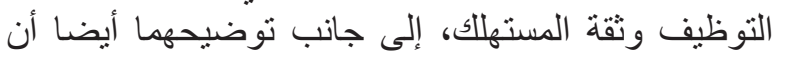

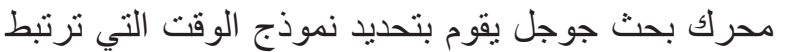

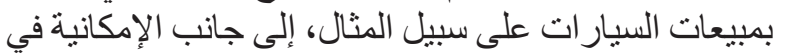

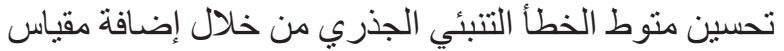
اتجاهات جوجل للبحث المعاصر.

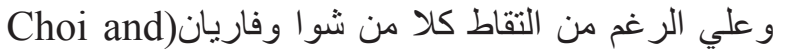

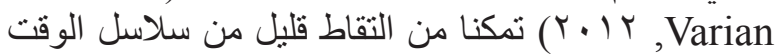
الاقتصادي المعين، إلا أن المدخل الذي التي اتبع يمكن تطبيقه

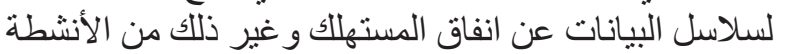

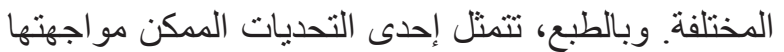
في تواجد فئات عديدة أو آلاف تساؤلات البات البحث المختلفة التي قد تنتبأ بالإنفاق في فئات أو تجمعات مختلفة. ولذلات آلك اقتر

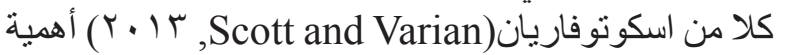
تطبيق الباحثين مدخلا آليا متضمنا أدوات الت التعلم الإحصائية

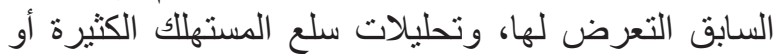
الضيقة إلى جانب سلسلة الوقت القصير لهير في هذا الإطار يمكن الثك في شيو عو وانتشار أنو اع الكثافات

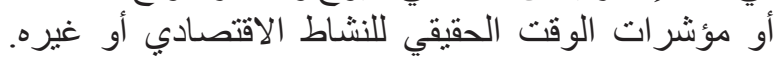

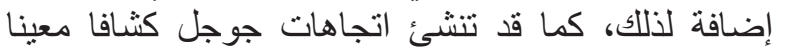

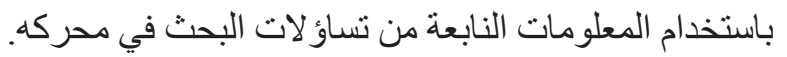

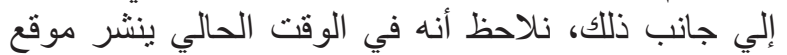
التواصل الاجتماعي تويتر Twitter كثافا يو ميا مبني علي لئي

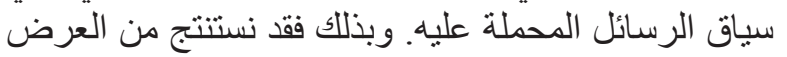

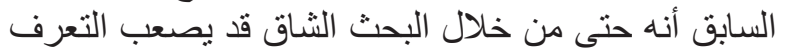

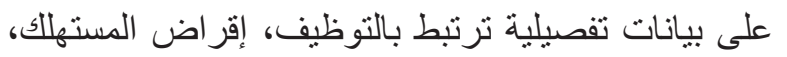

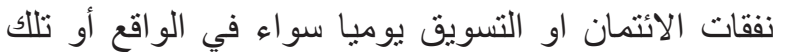

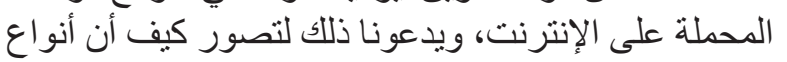

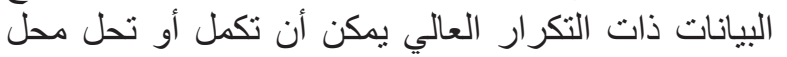

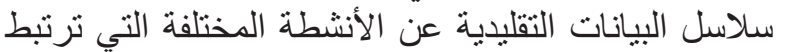
بحياة ومقدر ات المواطنين.

\section{الحكمة تحسين عمليات وخدمـات المصالح والأجهزة}

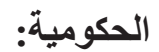


الرثال، قد يكون في الإمكان تصور الجدال النفعي بأن

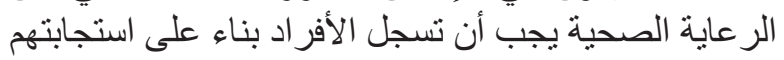

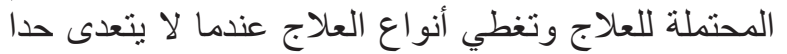

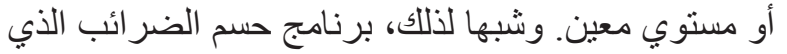

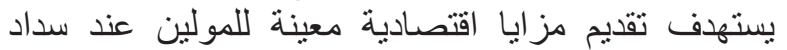
مستحقاتهم الضريبية المتأخرة قد يكون الكثر فعالية عندما يستهدف للعائلات مثلا.

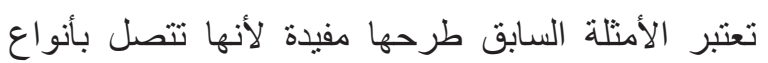

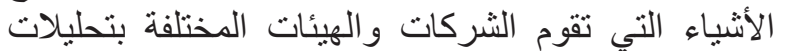

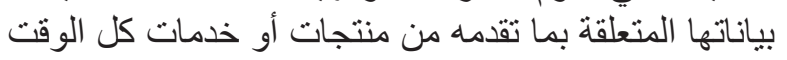
ترتبط بعملائها ومستهلكيها وكيفية جذاتبهم وحثنهم للإقبال

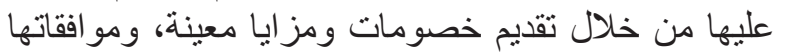
على طلبات التأمين و الإقر اض عند تلبيتهم معايير محددة. 7. الفرص التي تقدمها ثورة البياتات الكبيرة على السياسات التخطيطية والتنموية:

فيما يتعلق بالسؤ ال عن كيف تئثر ثورة البيانات المعاصرة على البحوث المرتبطة أساسا برسم السياسات التخطيطية

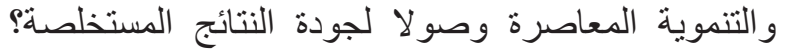
إلي جانب تحديد جودة الطرق المستخدمة في تحليلاتها

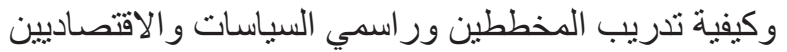

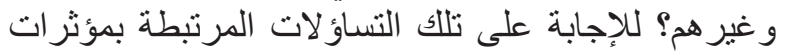
ثورة البيانات الكبيرة وتحليلاتها نلاحظ أو لا أن التأثير الأكثر

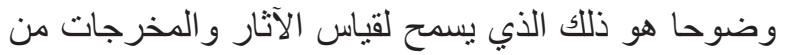

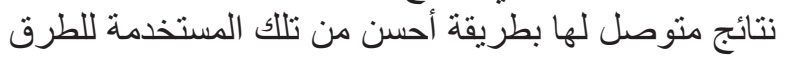

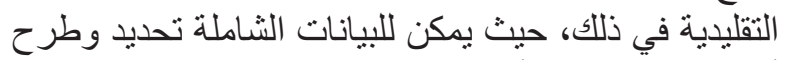

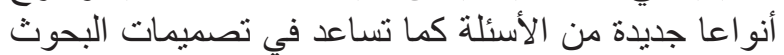

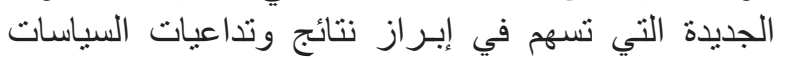

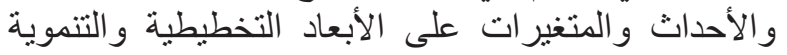

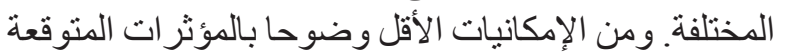

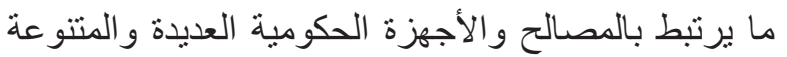

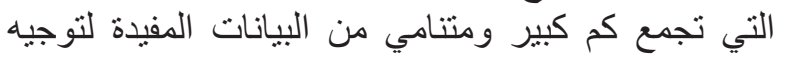

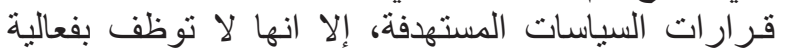

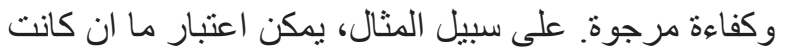

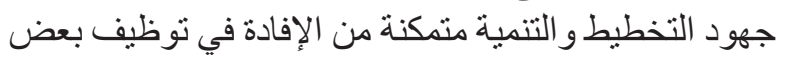
أساليب تنقيب البيانات على تحليلاتها المختلفة أم لا، ولماذي الماذا

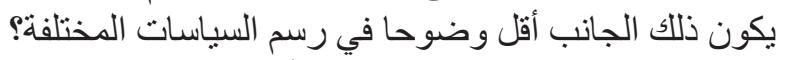
هذا القصور الواضح في توظيف الأساليب الآلية المتقدمة ما زال هو السائد في تحليلات البحوث البحت القائمة حتى الآن.

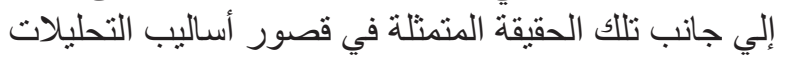

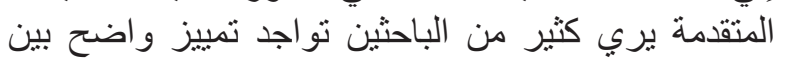

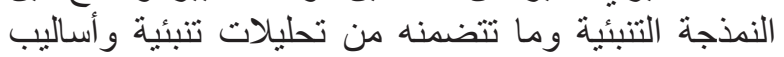
الاستدلال السبيية، ونتيجة لمداخل التعلم الاحصائي الرئية والهن تقتصر المساهمة المتوقعة. و وعلي ذلك يمكن التفكير الجدي التي التين

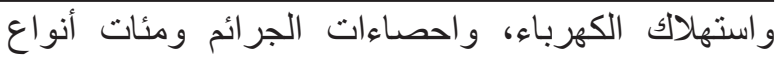

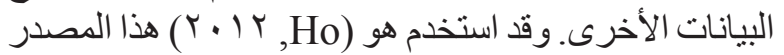

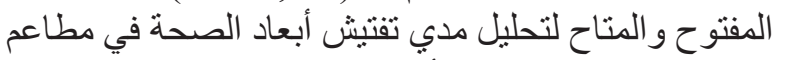

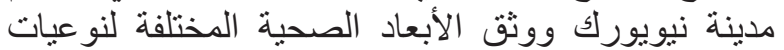

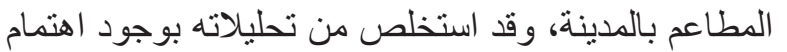

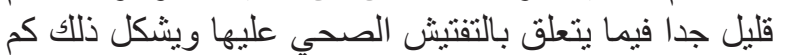

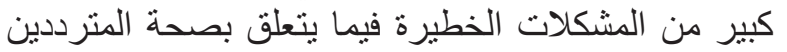

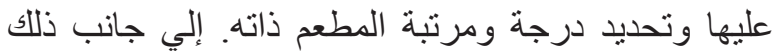

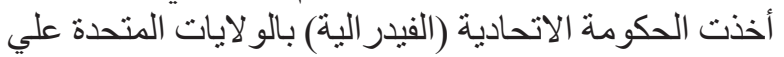

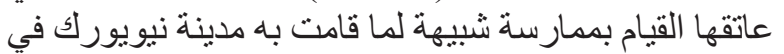

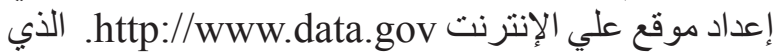
وفر آلاف مجمو عات البيانات الحكومية واتاحتها للمو اطنين المهتمين في البحث و التحليل و الإعلام. 0/ ع معلومات المنتجات والخدمات: معظم تطبيقات بيانات شركات القطاع الخاص السات السابق مناقتنها تستخدم النمذجة التنبئية فيما يتعلق بآلية عمليات التيات

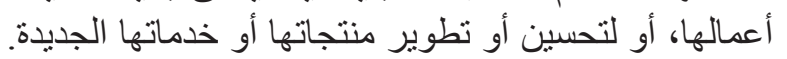

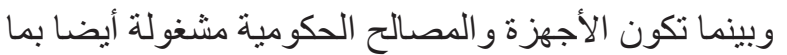

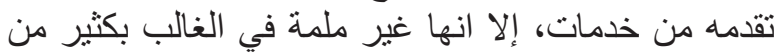

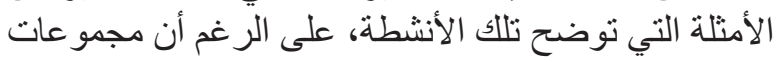

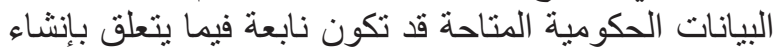
أنو اع منتجات المعلومات الثنائعة أيضا في القطاع الخاص. لهاص.

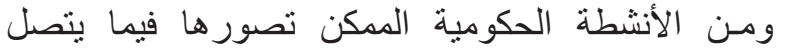

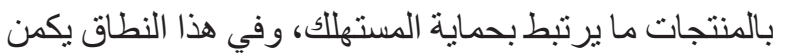

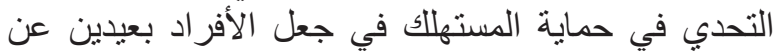
اتخاذ قر ارات يصلون لها من خلال إمكانية التنبؤ ثم يتأسفون التان

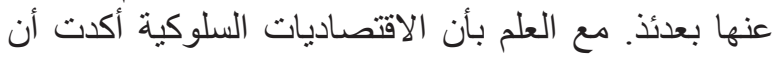

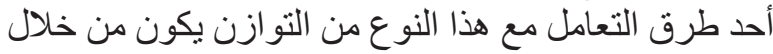

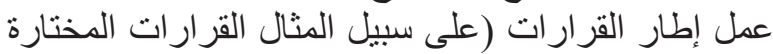

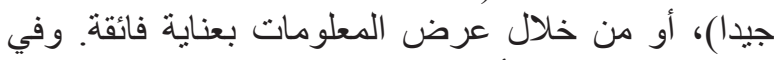

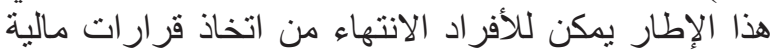

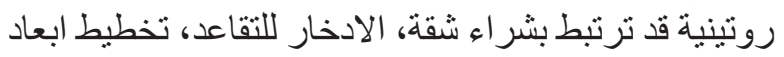

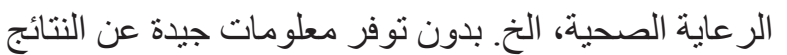

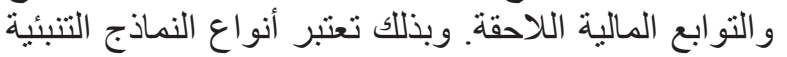

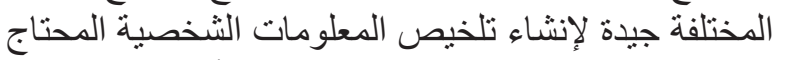

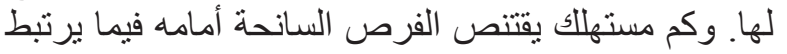

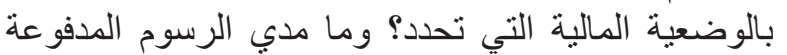

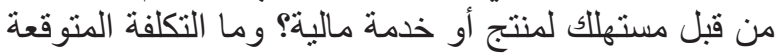

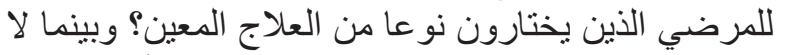

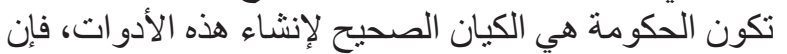
المعلومات التي تجمعها تكون مفيدة بالتأكيد.

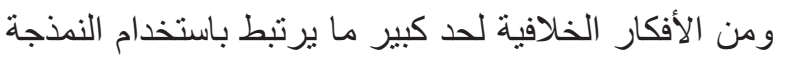
التتبئية لتحسين الخدمات الحكومية المستهدفة. على سبيل 
القطاع الخاص ما يرتبط بما قامت به شركة أوريجون للر عاية

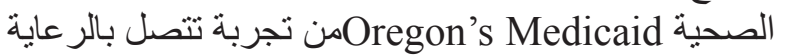

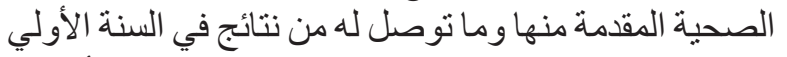

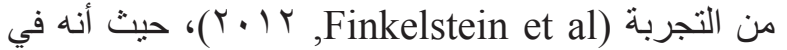

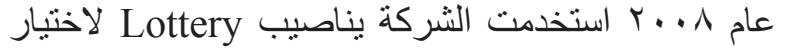
مجمو عة من الأفر اد المؤهلين للانضمام للتأمين الصحي التئي تقده الثركة. وقد أدي هذا اليناصيب تجربة النية طبيعية كبيرة

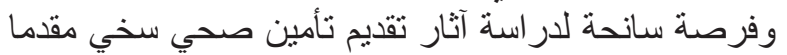
مز ايا للملتحقين به. وقد جمع الباحثون نتائج اليناصيب وبئي

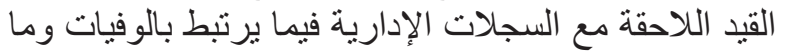

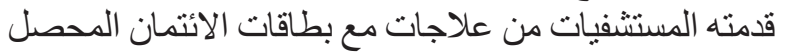

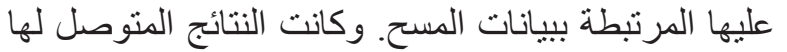

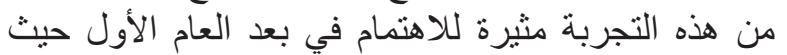

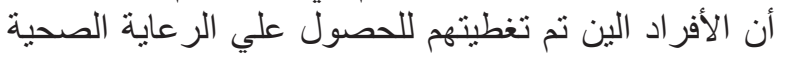
Medicaid

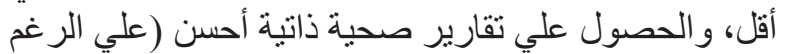
من ان الدراسة اللاحقة لنفس المؤلفين وجدت دلئ دليل تحسين

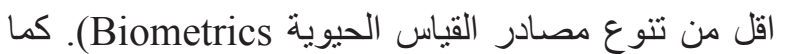

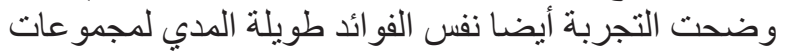

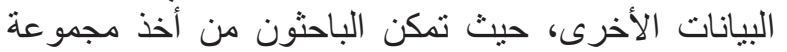
فرعية من سكان أو جمهور و لاية أوريجون لاحنة الاحقة وتحديد الخديد مدي تخصيصات العلاج المقدمة لهم من قبل مستشفيات

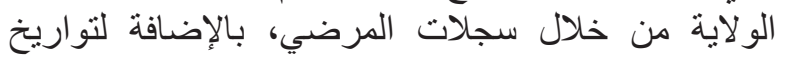

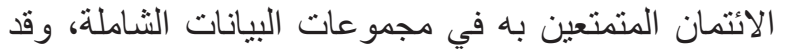

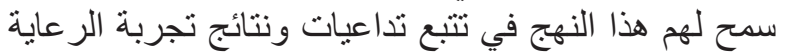
الصحية Medicaid من خلال استخدام عدد من المقاييس المختلفة

و المثال الثالث يرتبط باستخدام المقاييس لتحديد مؤشرات

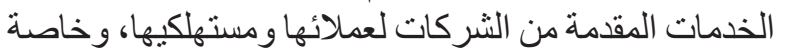

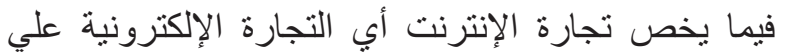

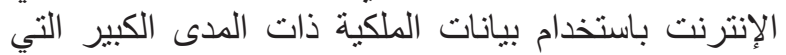

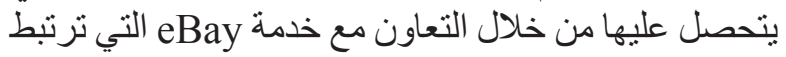

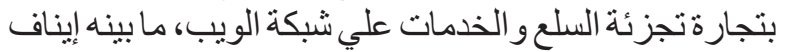

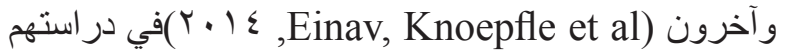

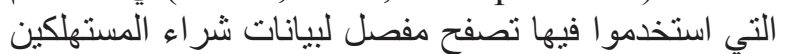

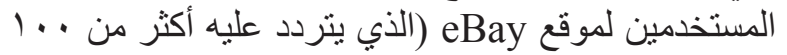

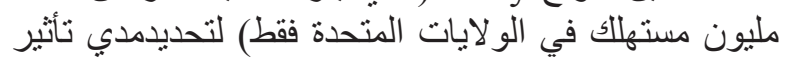

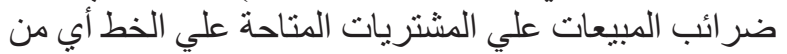

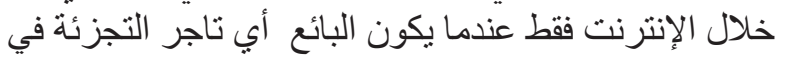

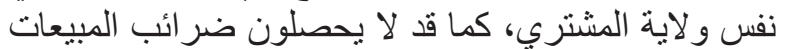

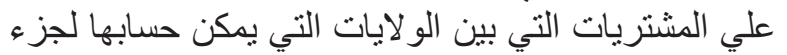

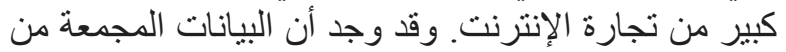

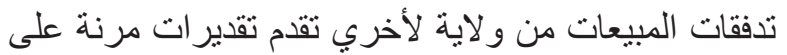

في تعليم و اكساب الاقتصاديين و الباحثين مهار ات وكفاءات

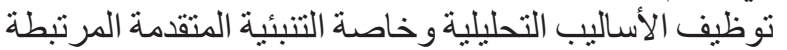

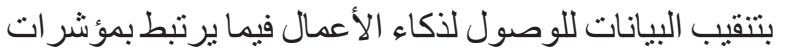

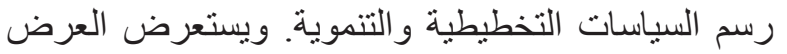

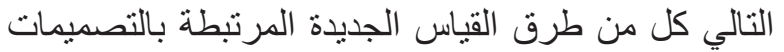
البحثية ومعالم تأهيل وتنمية القوي العاملة المتطلعة بذلكي لكالك.

1/ ا طرق القياسات الجديدة المرتبطة بالتصميمات البحثية: تعتبر مجموعات البيانات الإدارية الكبيرة النطاق وبيانات شركات ومنشآت اقطاع الخاص والقات القطاع العام الجديدة

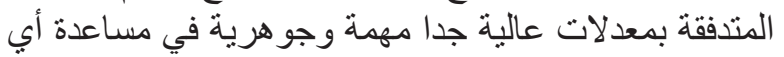
تنوع في تصميمات البحوث الجديدة وخاصة التهات التطبيقية منها. ومن الأمثلة البارزة في هذا الاتجاه الدراسة التي قام بها كل من شيتي وفريدمان وروكوف الإن

عن (Y.1), Chetty, Friedman and Rockoff)

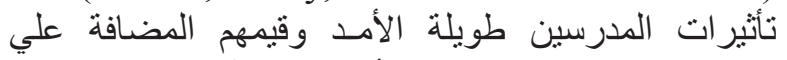

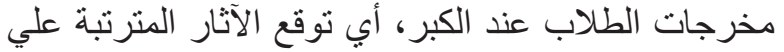
ضرورة توافر مدرسين أحسن علي العملية التعليمية في الدئية

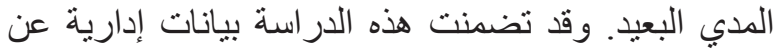

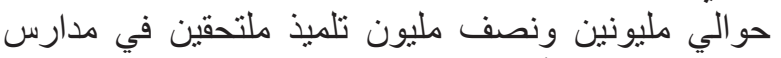

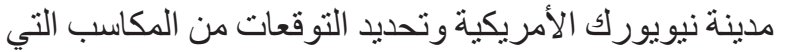
يحصلون عليها عند الكبر بعد عشرين عاما، وكان التساؤل

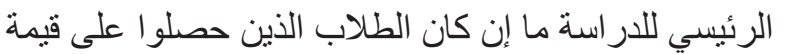

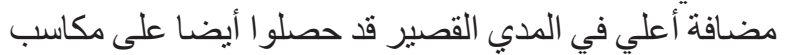

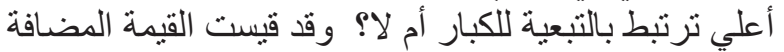

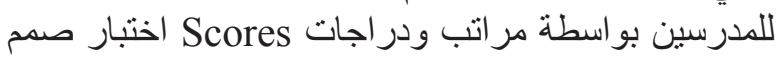
لذللك، الذي استنتج عددا من النتائج المثيرة للانتباه التي يمكن استخلاص فو ائد عديدة منها تتعلق بتحليلات البيانات النتان الإدارية ذات النطاق الكبير كما يالي: أو لا: القدرة علي ربط بيانات نتائج الاختبار القيمة الضافة الضئة للمدرسين وسجلات الضر ائب اللاحقة لعدد كبير من الطلاب الطاب

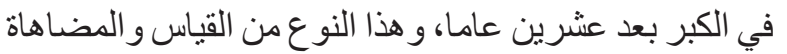

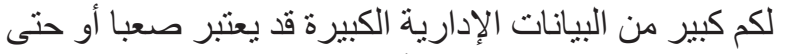

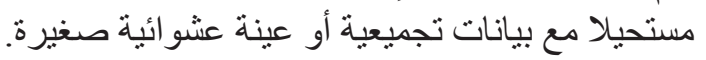

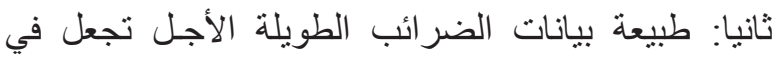

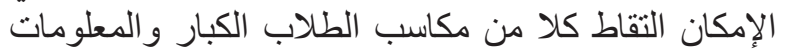
عن أباءهم في الفترة التي يعتمدون فيها عليهر. ثالثاو أخيرا: طبيعة بيانات درجـات أو مراتب الاتبن الاختبار

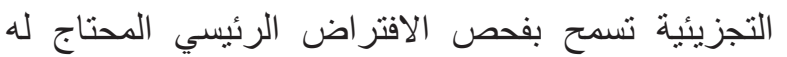
للتعريف أن الطلاب لائ يوز عون على المدرسين وفقا لمقدرتهر

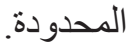
ومن الأمثلة الأخرى الحديثة التي تستخدم كلا من البيانات

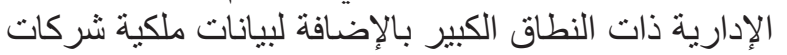


تنشيط وتقوية النتائج و الافتراضات الرئيسية. فقد استخدم

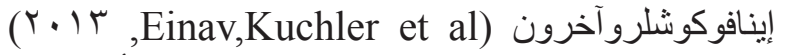

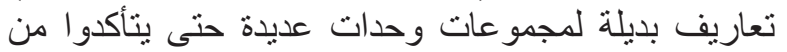

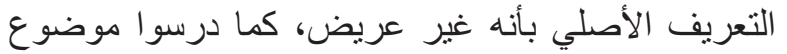

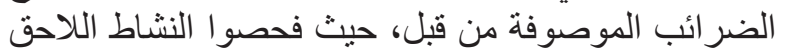

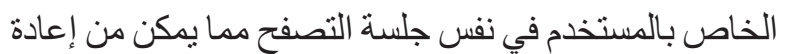
تأكيد التفسير النسبي للنتائج المتوصل فلفي لها.

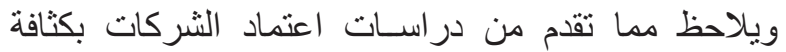

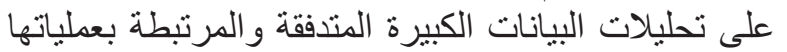
اليومية، أنه أصبح من الأسهل والأكثر فعالية لهان الكانية القيام

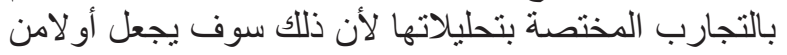

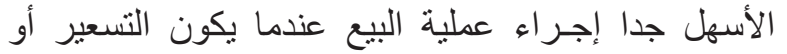

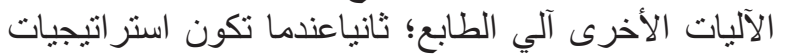

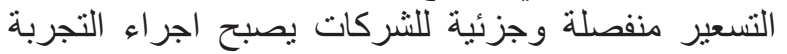

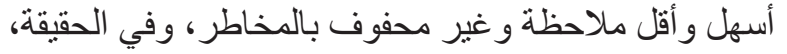

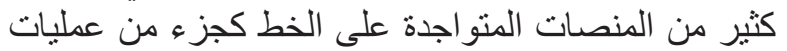

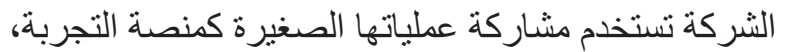

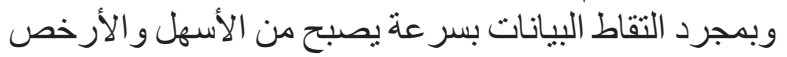

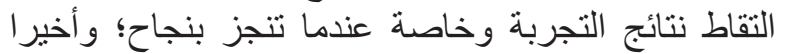
مع الاستراتيجيات الآلية يصبح مدكنا للشركات استخد استخدام

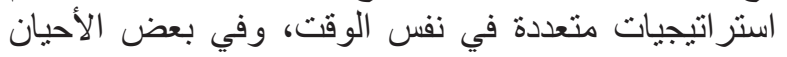

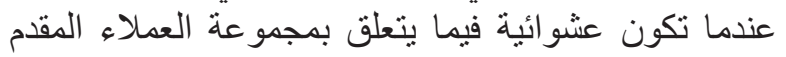

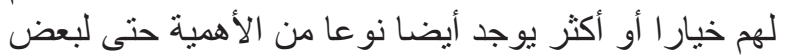
التجارب العشو ائية الظاهرية. ك/ r تأهيل وتتمية المخططين والباحثين في السياسات التخطيطية و التنموية: وتمية

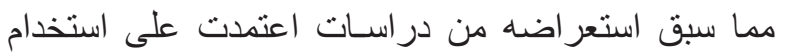

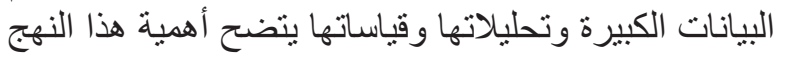

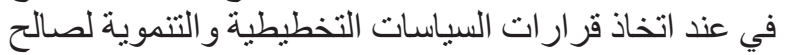

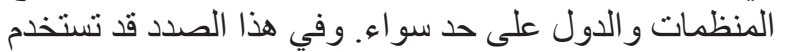

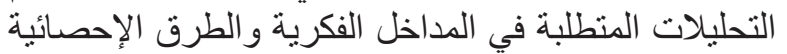

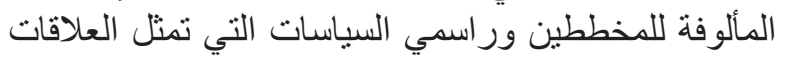

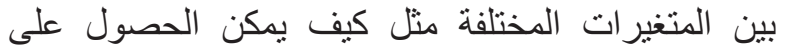
علاجات معينة، الالتحاق بالمدرس في المراحل التلفي التعليمية

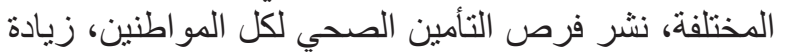

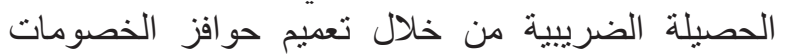

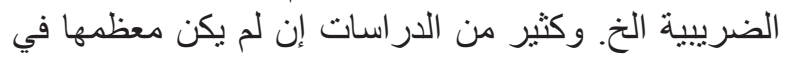

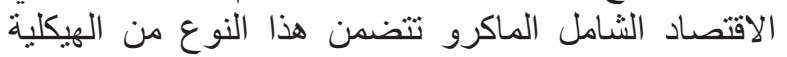

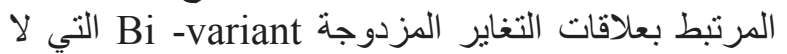

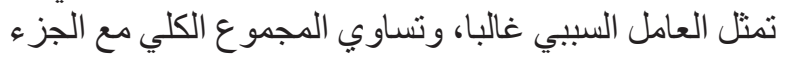

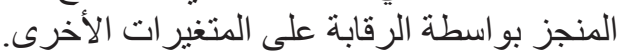

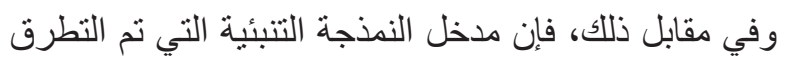

ضر ائب المبيعات، على الرغم من أن تصفح البيانات المفصلة

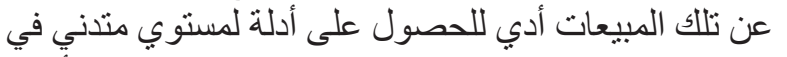

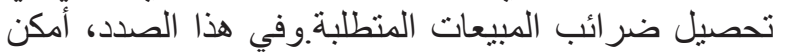

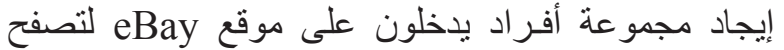

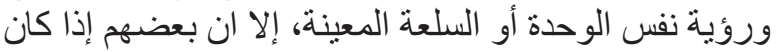

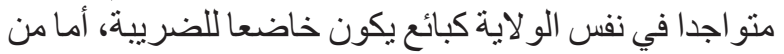

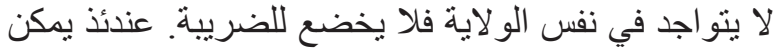

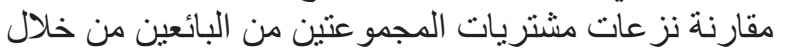

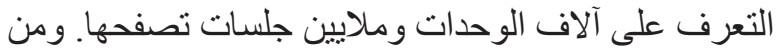

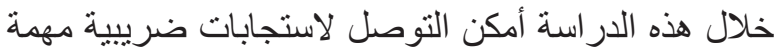

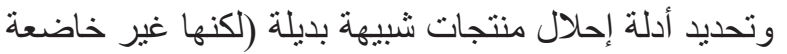

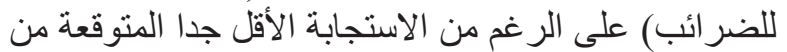
تحميلات سعر تجزئة السلعة.

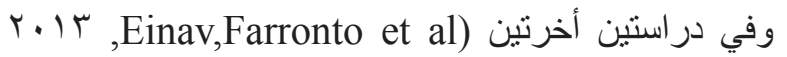
وEinav, Kuchler et al\&

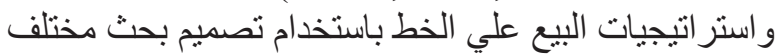

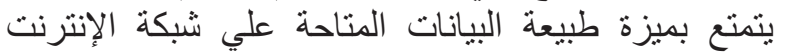

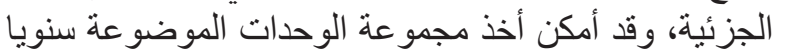

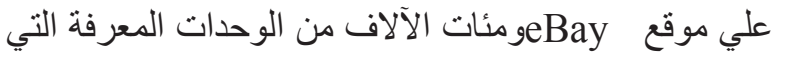

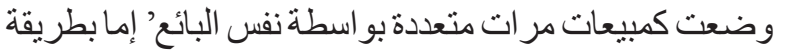

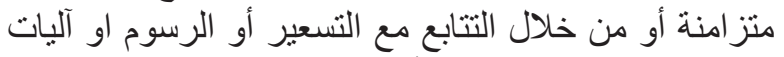

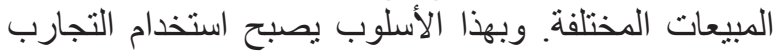

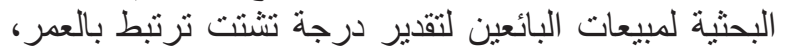

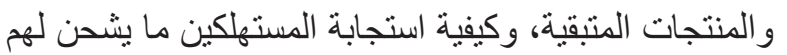

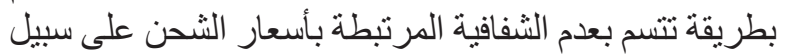

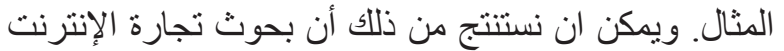

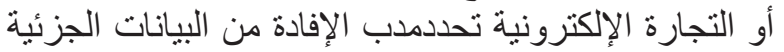

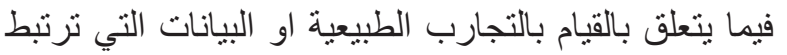

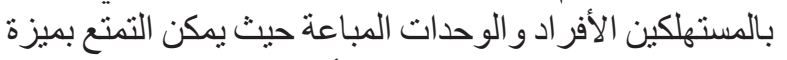

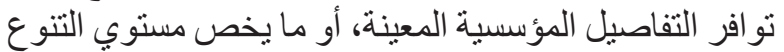

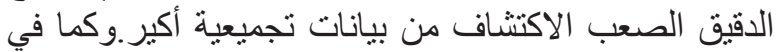

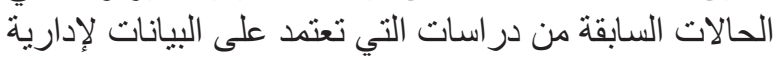

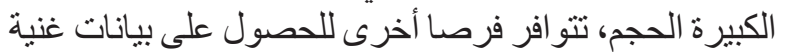

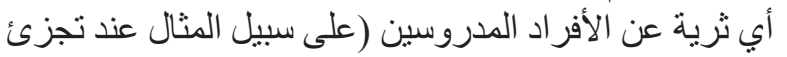

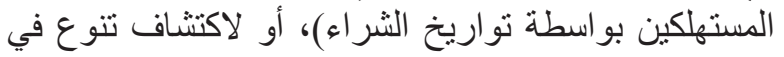

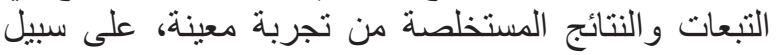
المثال إحلال وحدات مختلفة في حالة تغير السعر. ومن الأوجه الأخرى المرتبطةباستخدام المقاييس في التحليلات

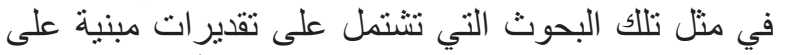

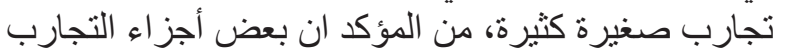

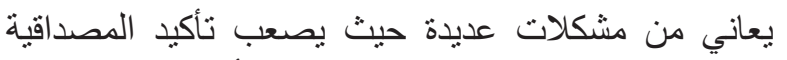

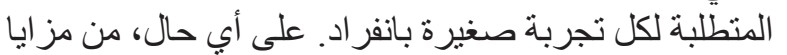

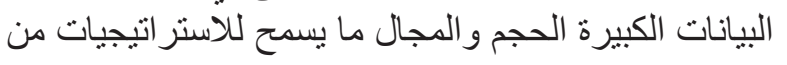


بها. على سبيل المثال، معدلات مخاطر الصحة تقدم خريطة

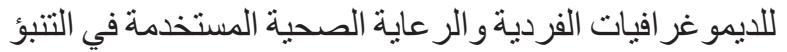

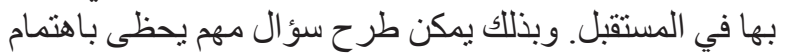

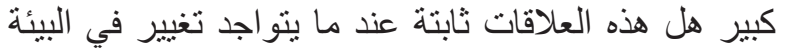

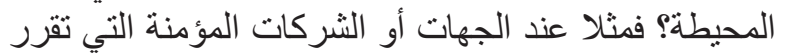

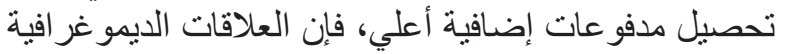

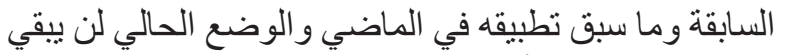

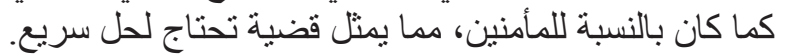

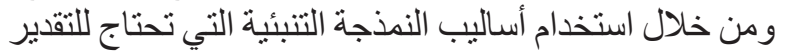

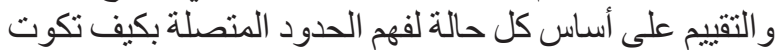

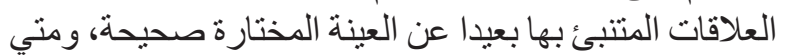
تغير السياسة هذه العلاقات.

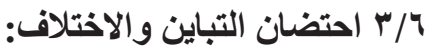

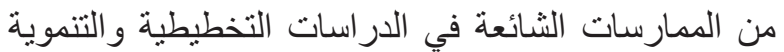

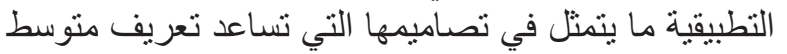

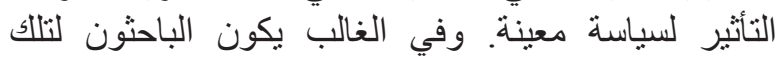

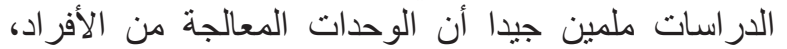

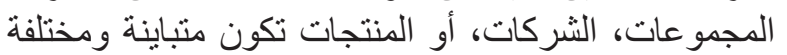

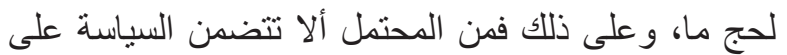

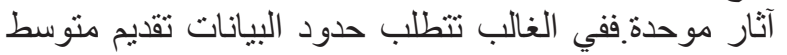
تللك الآثار، وحتى مع المستوي الدقيق الميكرو فغن التركيز

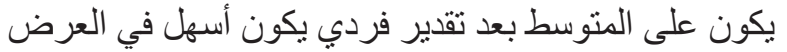

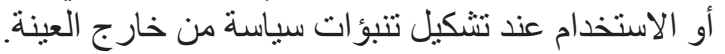

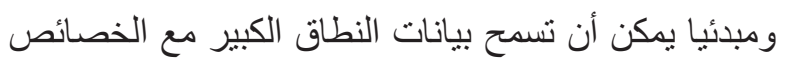

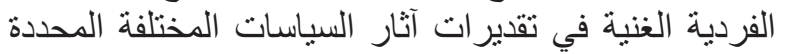

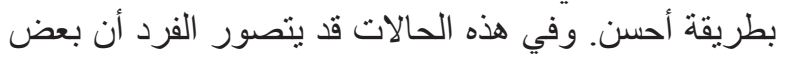

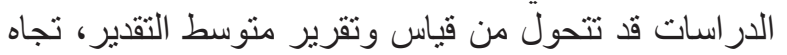

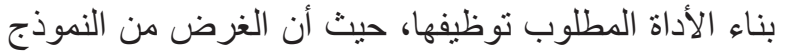

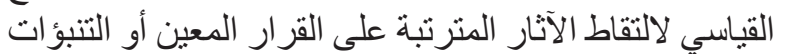

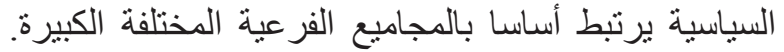

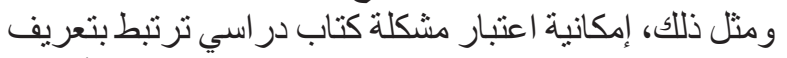

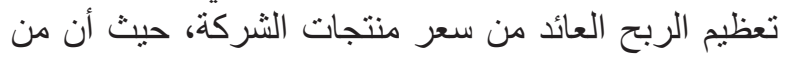

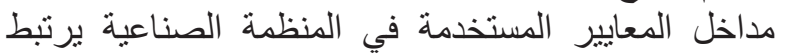

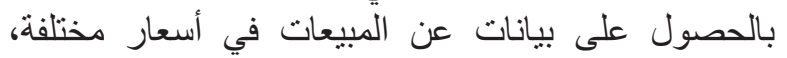
ومحاولة عزل التنوع في الأسعار التي تعرف مدي استجابتها

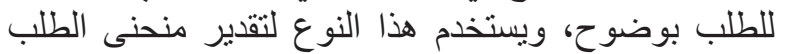

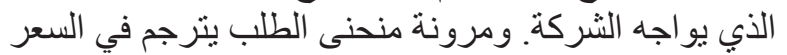
الأمثل الممكن ان تتبناه تكاليف الثركة الثنة مما تقدم يمكن اقتر اح أن للشركة بيانات عن عملائها الذين

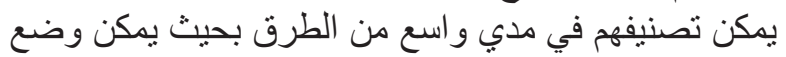

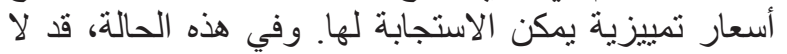
ير غب الباحث تقدير مرونة فردية، بل بدلا من ذلك فئل يطور

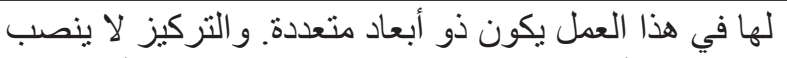

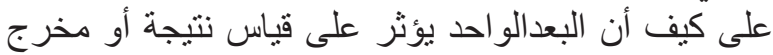

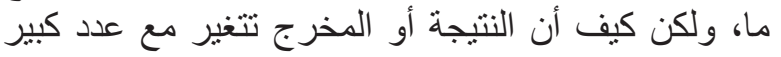

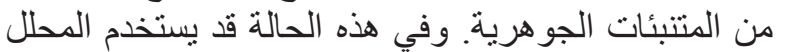

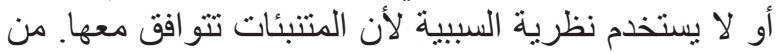

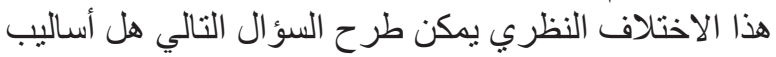

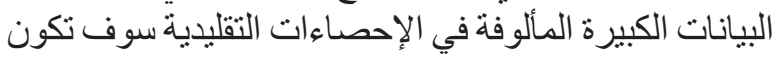
مفيدة في البحوث التخطيطنية و التنموية؟ التهات من المحتمل أن تكون إجابة ذلك التساؤل بنعم أب إنها إيجابية،

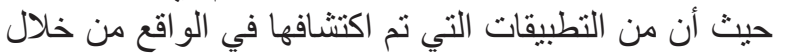

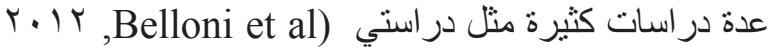
( $Y$. I , Belloni, Chernozhukov and Hansen\& بينت أن أساليب تعلم الآلة السابق التعرض لها بالتفالتصيل في

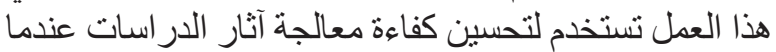

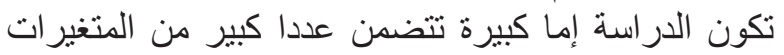

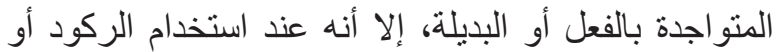

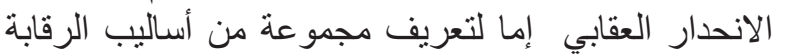

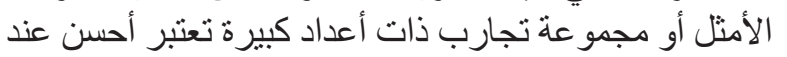

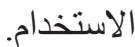

ومن استخدامات النمذجة التنبئية الأساسية ما يرتبط بتباين

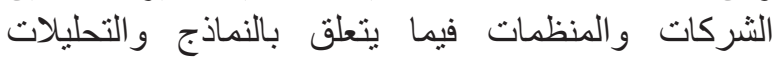

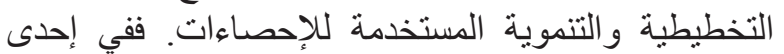

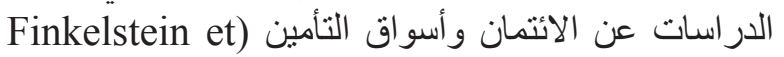

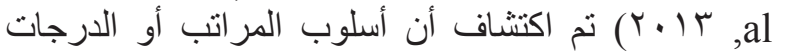

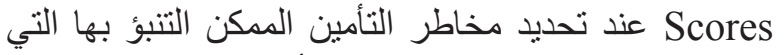
تلخص التباينات والاختلافات بين الأفراد تعتبر قليلة نسبيا،

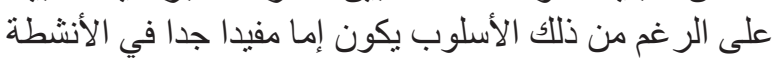

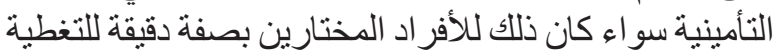

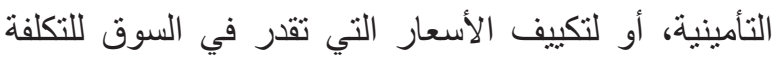
المرتبطة بالاختلافات المحتملة المقدرة للأفر آد المأمنين. وفي تلك الأمثلة من الدراسات السابقة، يتضح أن الباتهات الباحثين

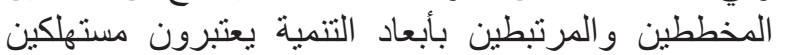

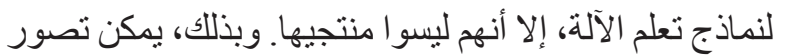

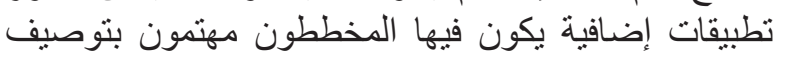

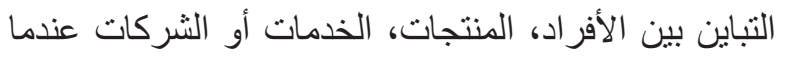

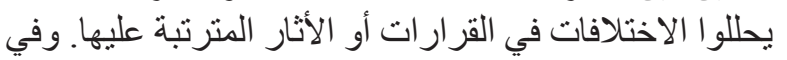

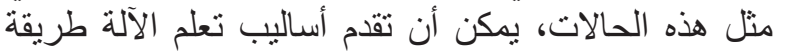

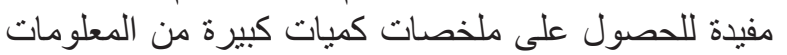

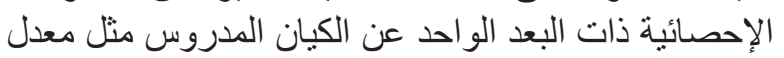

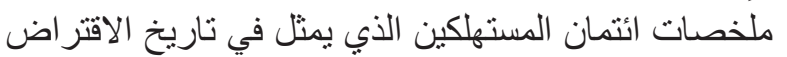

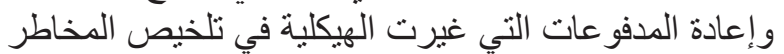

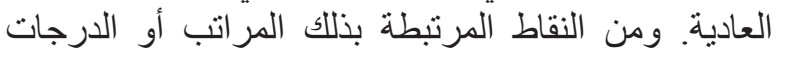

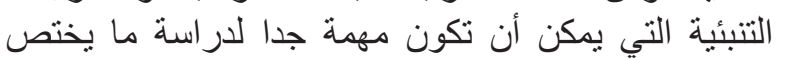


التأمينات الاجتماعية، الدخول، الربط الضريبي، الخ. وقضايا الخصوصية التي ترنبط بكميات البيانات الكبيرة تعتبر مهمة التباتيات

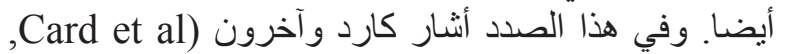

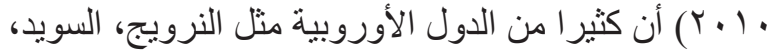

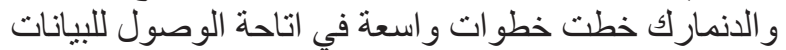

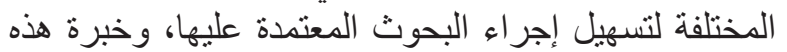

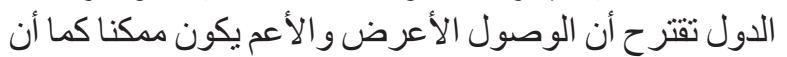

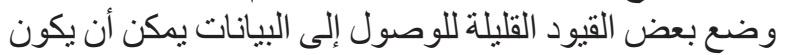

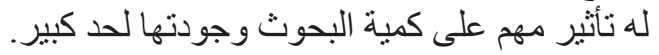

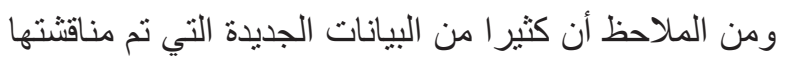

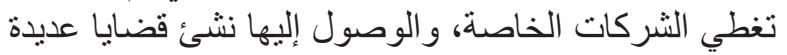

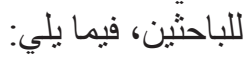

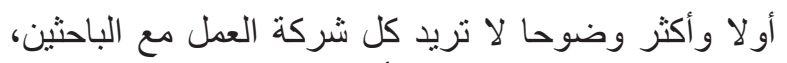

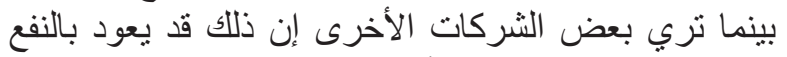

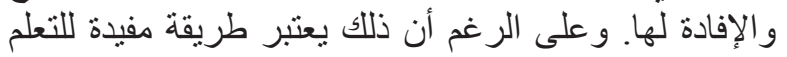

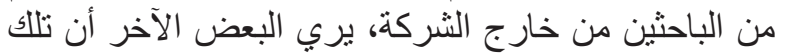

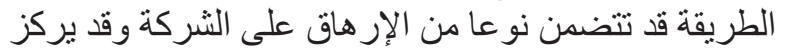

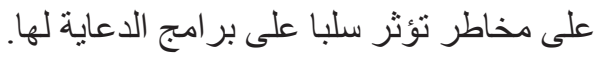

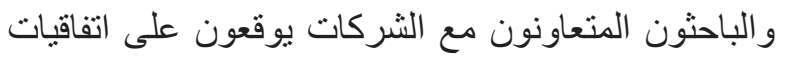

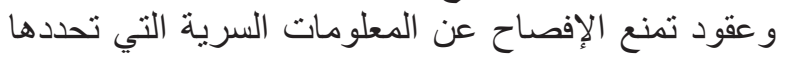

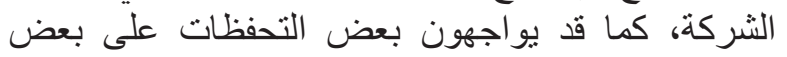

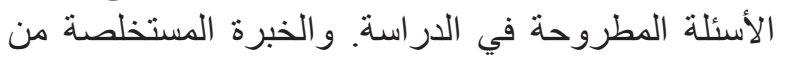

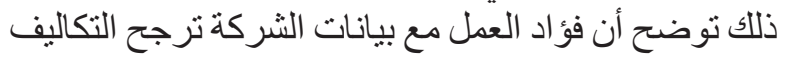

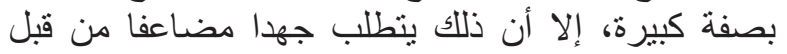

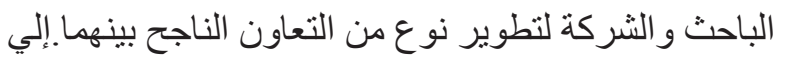

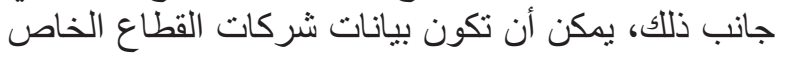

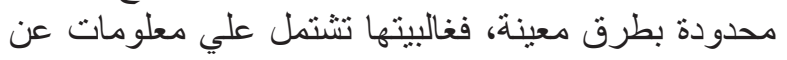

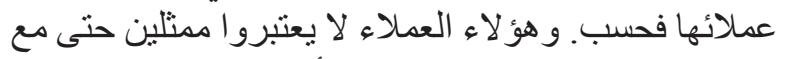

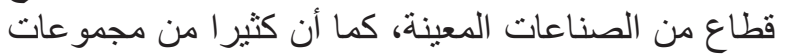

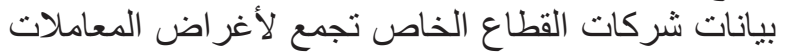

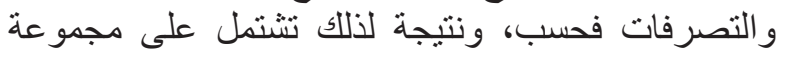

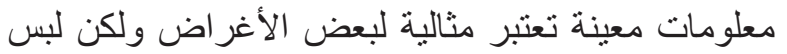

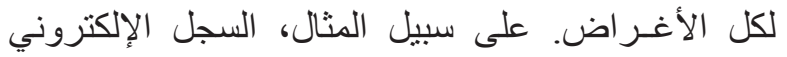

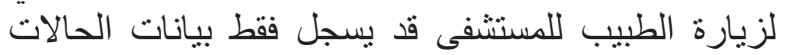

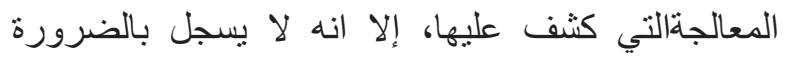

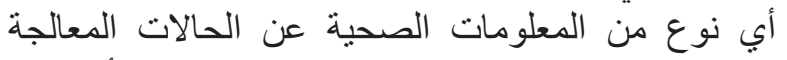

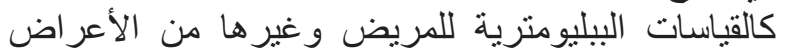

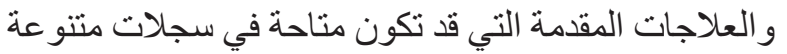
ومنفصلة عن المرضي. نفس الثيء بالنسبة لسجل فئل معاينة

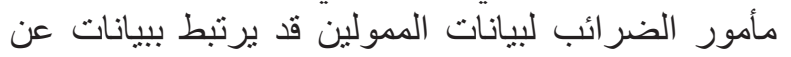

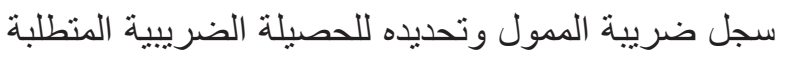

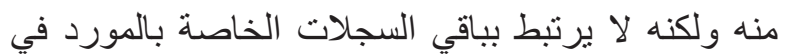
الجهات الأخرى التي تحدد أبعاد دخله و الاير اد المتحصل بالِ فئل
ألجوريثم يقوم بتصنيف المستهلكين في أنواع عديدة، ويقدر

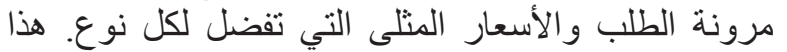

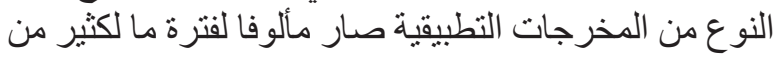

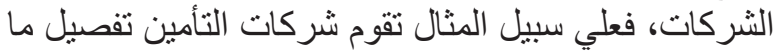

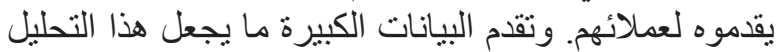

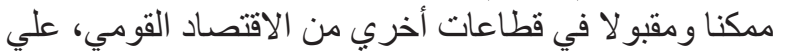

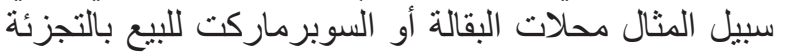

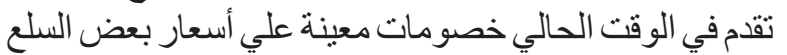

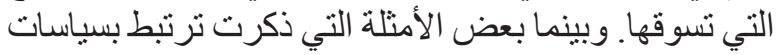

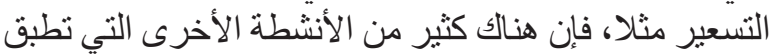

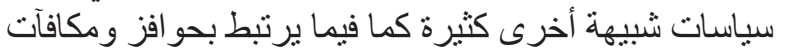
المقدمة من شركات وأجهزة التأمين والئرة الرعاية الصحية،

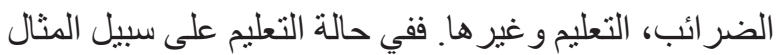

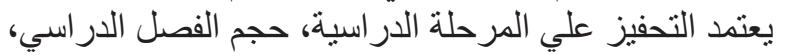

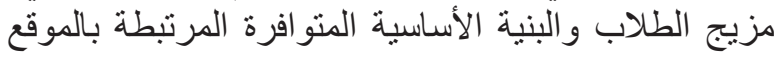

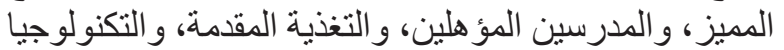

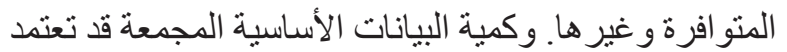
علي كل مجمو عات تللك الأبعاد و غير ها من بيانات الجمهيات الإنهور المستهدف، وبذلك يمكن استخدام أساليب التحليلات التنبئية

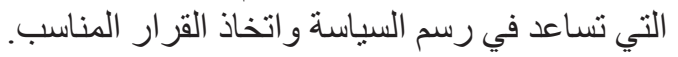

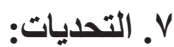

توجد تحديات كثيرة تواجه المخططين ومتخذي قرارات السياسات المستخدمة الذين يو اجهون بكم كبير من مجمو عات الهيه البيانات الكبيرة و المتجددة باستمر ار ويأملون في في الاستفادة

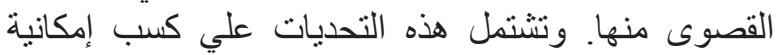
الوصول لهذه البيانات، تطوير إدارة وبرمجة البهل البيانات المحتاج

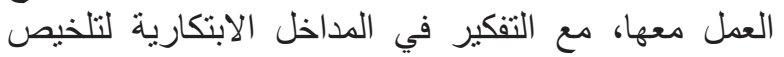
وو صف و تحليل المعلو مات المتضمنة في هذه البيانات الكبيرة. وفي إطارتحديات الوصول للبيانات، فإن الدراسات المتعلقة الإنة

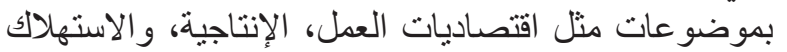

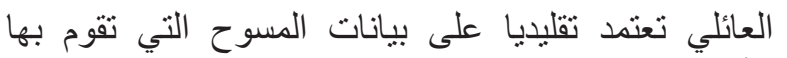
الأجززة الحكومية في العادة كما في حالات التعداد السكاني. وتوجد لكثير من هذه البيانات بروتوكولاتيات فئلات منشأة لكيفية

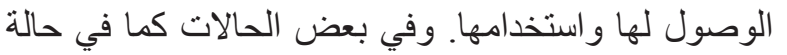

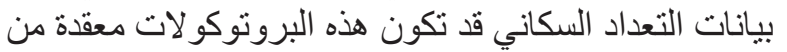

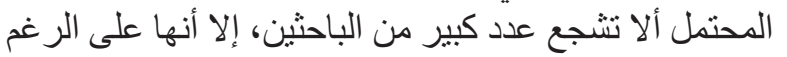

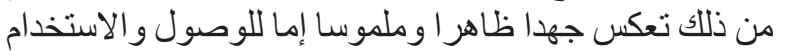
أو الحجب للسرية التي تتصف بها من وجهة النظر السياسية

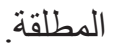

وما زالت كثير من النظم المتاحة حاليا تختص بالبيانات

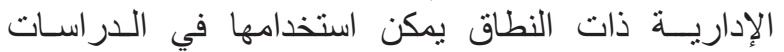
التخطيطية والتنموية مثل تللك المتعلقة بالرعاية الصحية، 
و عيوب البيانات المتاحة، وتطوير الاستر اتيجيات و الطرق

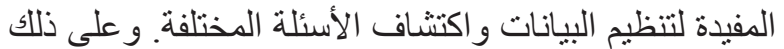

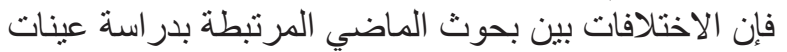

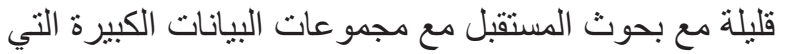

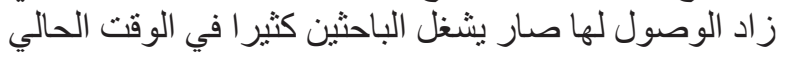
وسوف يكون له مردودا علي السياسات التخطيطية والتنموية لإنية

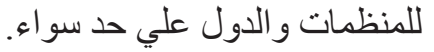

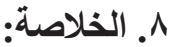

مما سبق من عرض يتضح وجود قليل من الثّك في أنه في السنوات المقبلة سوف تغير ظاهرة البيانات الكبيرة

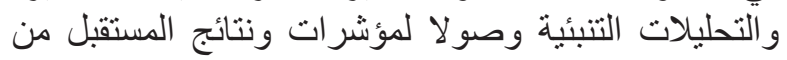

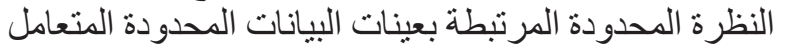

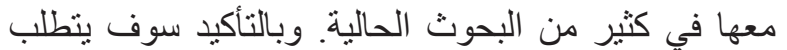

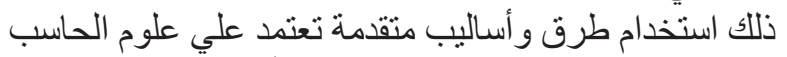

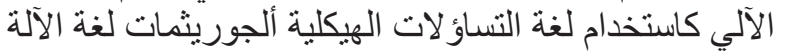
و غبر ها من أساليب تنقيب البيانات لاكتشاف المعرفة المتطلبة. وقد ظهر حديثا مصطلح 》علم البيانات) الـذي صار يشير لمجال علمي نامي مهتم بجمع كميات بيانات كبيرة

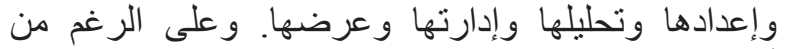

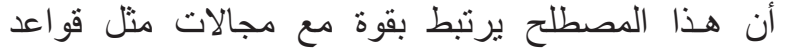

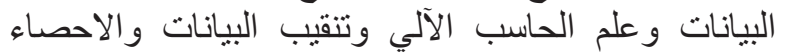

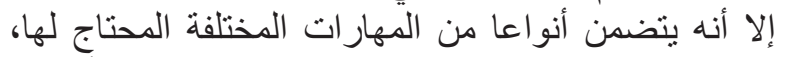

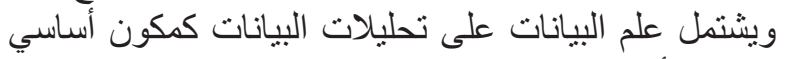

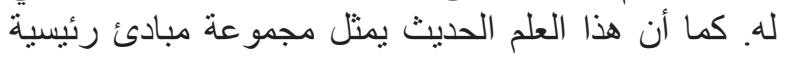

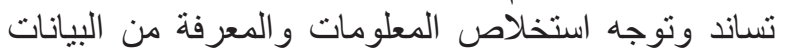

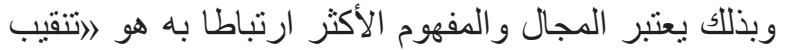

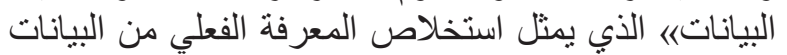

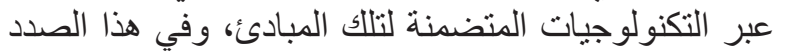

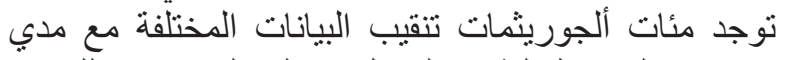

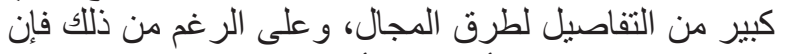
علم البيانات يتضمن أكثر من ألجوريثمات تنقيب النيات البيانات.

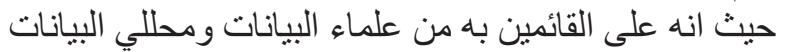

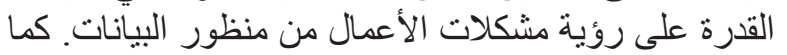

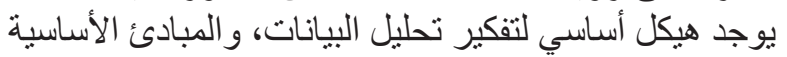

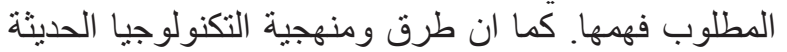

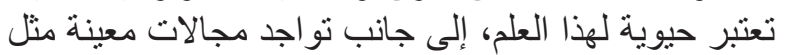

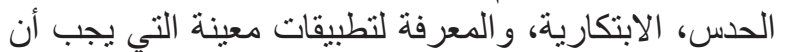

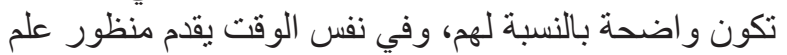

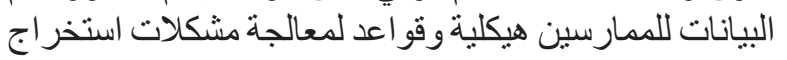
المعرفة المفيدة من البيانات الكبيرة المتاحة.

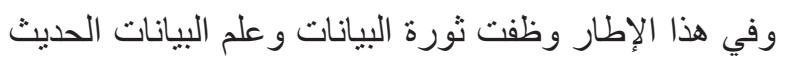

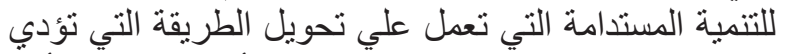

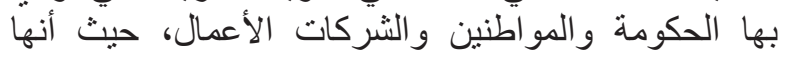

عليه منها وكل ذلك يمثل تحديات تواجه محللي بيانات

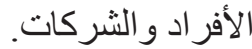

وفيما يتعلق بتحديات إدارة البيانات واستخدام الحوسبة، فمن الطرق التي وصفت من قبل بعض المعلقين فيما يتعلق

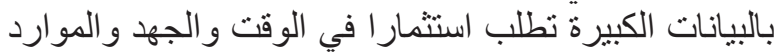

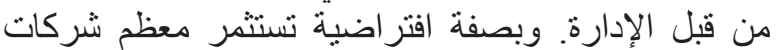

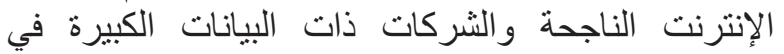
قطاعات الاقتصاد الوطني الأخرىفي أنشطة ترنبط بتخزين البيانات ومعالجة البيانات الموزعة وغيرات الإفيا، كما تستثر

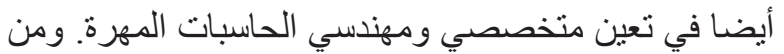

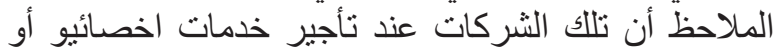

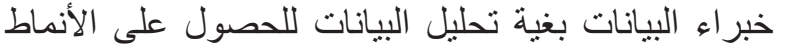

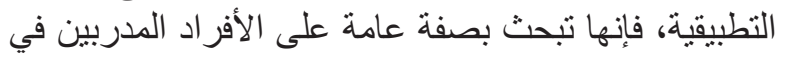

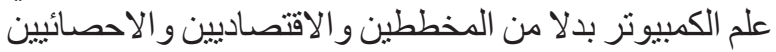
للقيام بذلك. و هذا يحدد أن مستقبل المخططين و الاقيت الاقتصاديين و الاحصائيين الر اغبين العمل مع مجمو عات البيان البيانات الكبيرة يتطلب منهم التعرف على الأقل لبعض أبعض أدوات اتع علم الكمبيوتر

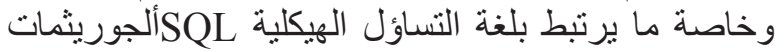

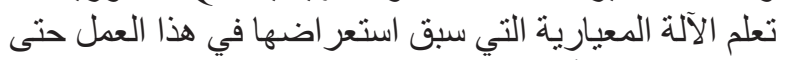

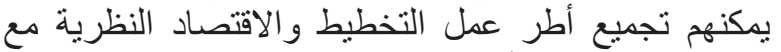
القدرة في تطبيق الأفكار الفعلية بكفاءة وسرعة لفئ فيما يتصل بالتعامل مع البيانات الكبيرة. وفيما يتعلق بتحديات طرح الأسئلة الصحيحة، تتمثل بعض بانس الملاحظات الإضافية بالارتباط و العمل مع مجمو عات بيانات كبيرة غنية جدا التي لا تكون هامشية أو ثانوية لاكتشاف الأنس الأسئلة

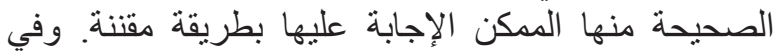
الماضي القريب، كان الباحث في مقدرنه فتح ملفات البيانات الإنه

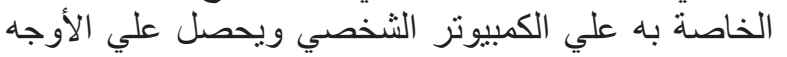

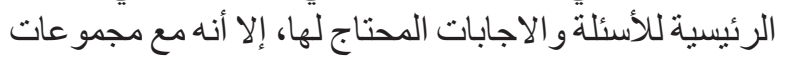

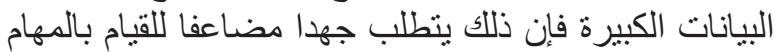
المدركة، مثل استخلاص وتلخيص بدائل فئل مختلفة واكتشاف

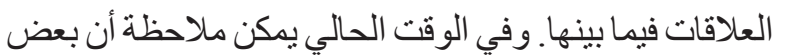

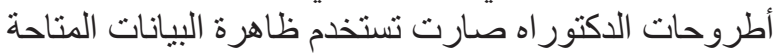

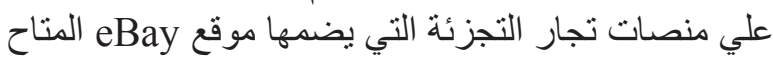

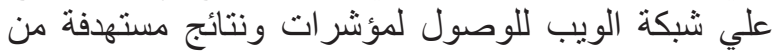

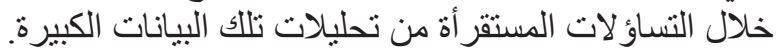

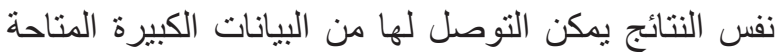

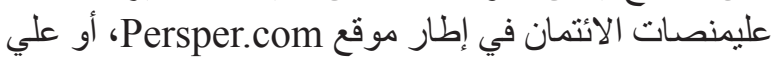
Airbnb. منصات الترويح و السفريات المتاحة علي موقات الإنعات

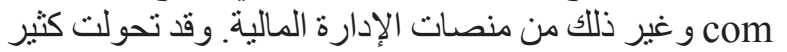

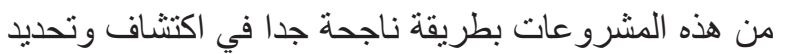

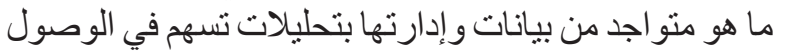

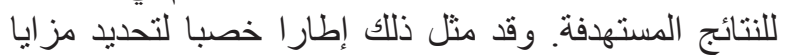


Record, No. 88, pp. 2-9.

-7. Einav, Liran, Farronto etal (2013). "Selection or moral hazard in health insurance." American Economic Review, Vol. 103, No. 1, pp. 178-219.

-8. Einav, Liran, Kochler, et al (2013). "Learning from seller experiments in online markets." Canbridge, MA: National Bureau of Economic Research [NBER Working Paper No. 17385].

-9. Einav, Liran, Knoefle, D. et al (2014). "Sales taxes and Internet commerce." American Economic Review, Vol. 104, No. 1, pp. 1-24.

-10. Finkelstein, Amy et al (2012). "The Oregon health insurance experiment: Evidence from the first year." Quarterly Journal of Economics, Vol. 127, No. 3, 1057-1106.

-11. Hastie, T. et al (2008). The elements of statistical learning: Data mining, inference and prediction. New York: Springer-Verlag.

-12. Imbens, G. et al (2011). Clustering, spatial correlation and randomization inference. Cambridge, MA; Harvard University Memo

-13. Jason Study Group (December 2008). "Data analysis challenges: JSR-08-142." [http://www.fas.org/irp/agency/dod/Jason/ data.pdf].

-14. Klenow, P. J. and Kryvstov, O. (2008). "State-dependent or time-dependent pricing: Does it matter for recent US inflation?" Quarterly Journal of Economics, vol. 123, pp. 863904.

-15. Piketty, T. and Saez, E. (2003). "Income inequality in the United States, 1913-1998" Quarterly Journal of Economics, Vol. 118, No. 1, pp. 1-39.

-16. Scott, J. and Varian, H. (2013). "Bayesian variable selection for now casting economic time series." San Diego, CA: ASSA Annual Meeting (Presentation ppt.).

-17. Varian, H. (2010). "Computer-mediated transaction." American Economic Review Papers and Proceedings, Vol. 100, No.2, pp. 1-10.
تعرف بالانفجار الحادث حاليا في توافر موارد البيانات

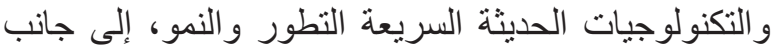

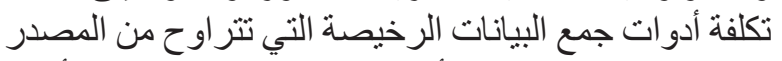
الضخم للبيانات إلى الأشكال الملتقطة بواسطة الأقمار الصناعية التي غيرت جميعها الطريقة التي تؤدي بهان بواليا الأعمال

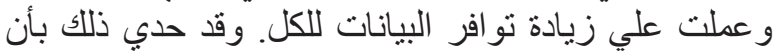
مجموعة الخبر اء الدولية عن ثورة البيانيات اليات للتنمية المستدامة

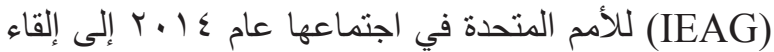

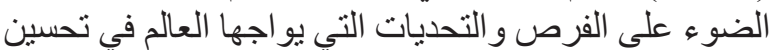
البيانات للتنمية المستدامة. وفي إطار ما سبق إثارته عن ثورة البيانات الحالية يصبح من المؤكد أن التحول الحالي في استخدام البيانات وتحلي ونيلاتها

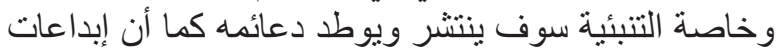

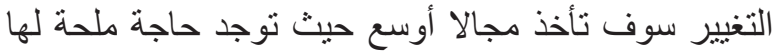

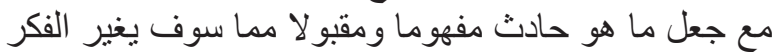
الإداري في إدارة الأعمال كليا.

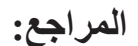

-1. Belloni, Alexander et al (2012). "Sparse models and methods for optimal instruments with an application to eminent domain." Econometrics, Vol. 80, No. 6, pp. 2369-2429.

-2. Belloni, Alexander, Chernoehukov, V. and Hanssen, C. (2012). "Inference on treatment effects after selection amongst high-dimensional controls." London: Centre for Microdata Methods and Practice [working Paper No. CWP10/12]

-3. Card, D. et al (2011). Expanding access to administrative data for research in United States. Arlington, VA: National Science Foundation Directorate of Social Behavior and Economic Science [NSF SBE 2020 White Papers].

-4. Cavallo, A. (2012). "Scraped data and sticky prices." Cambridge, MA: MIT [Sloan Working Paper].

-5. Chetty, R., Friedman, J. and Rockoff, J. (2011). "The long-term impacts of teachers: Teachers value-added and student outcomes in adulthood." Cambridge, MA: National Bureau of Economic Research [MBER Working Paper No. 17699].

-6. Choi, H. and Varian, H. (2012). "Predicting the present with Google trends." Economic 